\title{
叔丁基亚磺酰胺在天然产物全合成中的应用
}

\author{
李 颖 $a$ 马志强 $*, a, b$ 徐学涛 $*, a$ \\ ( ${ }^{a}$ 五邑大学生物科技与大健康学院 广东江门 529020) \\ ( ${ }^{b}$ 华南理工大学化学与化工学院 广东省功能分子工程重点实验室 广州 510641)
}

\begin{abstract}
摘要 叔丁基亚磺酰胺由于性质稳定、商业可得、价格合理、使用方便及参与反应的立体选择性好等优点, 受到化学家 的广泛关注. 总结了近年来利用手性叔丁基亚磺酰胺作为手性辅基诱导生成手性胺中间体在天然产物不对称全合成中的 应用, 主要分亲核试剂对叔丁基亚磺酰亚胺的加成及叔丁基亚磺酰基金属烯胺对亲电试剂的加成两部分进行介绍.

关键词 叔丁基亚磺酰胺; 手性胺; 全合成
\end{abstract}

\section{Application of tert-Butanesulfinamide in Total Synthesis of Natural Products}

\author{
$\mathrm{Li}_{\text {, Ying }}{ }^{a} \quad \mathrm{Ma}$, Zhiqiang $^{*, a, b} \quad \mathrm{Xu}$, Xuetao $^{*, a}$ \\ $\left({ }^{a}\right.$ School of Biotechnology and Health Science, Wuyi University, Jiangmen, Guangdong 529020) \\ $\left({ }^{b}\right.$ Key Laboratory of Functional Molecular Engineering of Guangdong Province, School of Chemistry \& \\ Chemical Engineering, South China University of Technology, Guangzhou 510641)
}

\begin{abstract}
The formation of chiral amine intermediates with chiral tert-butanesulfinamide and their applications in asymmetric natural product synthesis in recent years are summarized. tert-Butanesulfinamide has attracted wide attention from chemists because it is stable, commercially available with reasonable price, ease to use, and usually induces high diastereoselectivity in the reactions involved. This review is divided into two sections, including the addition of nucleophiles to $N$-tert-butanesulfinyl imines and the addition of $N$-tert-butanesulfinyl metalloenamines to electrophiles.
\end{abstract}

Keywords tert-butanesulfinamide; chiral amine; total synthesis

1997 年, Ellman 课题组 ${ }^{[1]}$ 报道了光学纯叔丁基亚磺 酰胺的制备方法, 并利用叔丁基亚磺酰胺诱导合成了手 性胺. 之后以手性叔丁基亚磺酰胺为手性辅基不对称合 成胺的方法受到化学家的广泛关注, 相关的研究蓬勃发 展，目前该策略已成为合成手性胺最广泛使用的方法之 - [2]. 利用手性叔丁基亚磺酰胺诱导合成手性胺的通用 步骤为: 首先叔丁基亚磺酰胺和醛或酮缩合生成叔丁基 亚磺酰亚胺, 新生成的叔丁基亚磺酰亚胺进一步与亲核 试剂发生不对称 1,2-加成反应引入胺的 $\alpha$ 位立体中心; 或者叔丁基亚磺酰亚胺在碱性条件下去质子化, 生成的 叔丁基亚磺酰基金属烯胺 ${ }^{[3]}$ 进一步与亲电试剂发生加成 反应，可以引入胺的 $\beta$ 位立体中心(Scheme 1).

利用叔丁基亚磺酰胺合成手性胺具有以下优 势 ${ }^{[2 e, 4]}$ : (1)叔丁基亚磺酰胺在温和条件下可以与多种醛
或酮直接缩合，以高收率得到稳定的叔丁基亚磺酰亚 胺; (2)由于叔丁基亚磺酰基的活化作用, 叔丁基亚磺酰 亚胺具有较强的亲电性, 可与多种亲核试剂发生高效的 加成, 从而转化为不同的含氮产物; 另外叔丁基亚磺酰 基与金属配位可以提高加成反应的立体选择性; (3)叔丁 基亚磺酰基也可以充当保护基，与甲酰基保护基类似， 并且它在强碱和过渡金属催化的条件下都能稳定存在; (4)叔丁基亚磺酰基可以方便地在盐酸等条件下脱除, 得到胺类化合物, 反应通常效率很高.

总结了近些年利用手性叔丁基亚磺酰胺作为手性 辅基诱导生成手性胺中间体在天然产物不对称全合成 中的应用. 根据引入立体中心的方式进行分类, 包括叔 丁基亚磺酰亚胺的 1,2-加成反应和叔丁基亚磺酰基金属 烯胺与亲电试剂的加成反应两部分.

* Corresponding authors. E-mail: cezqma@scut.edu.cn; wyuchemxxt@126.com Received June 15, 2020; revised July 23, 2020; published online July 30, 2020. Project supported by the Department of Education of Guangdong Province (No. 2019KZDXM035). 广东省教育厅基金基金(No. 2019KZDXM035)资助项目. 


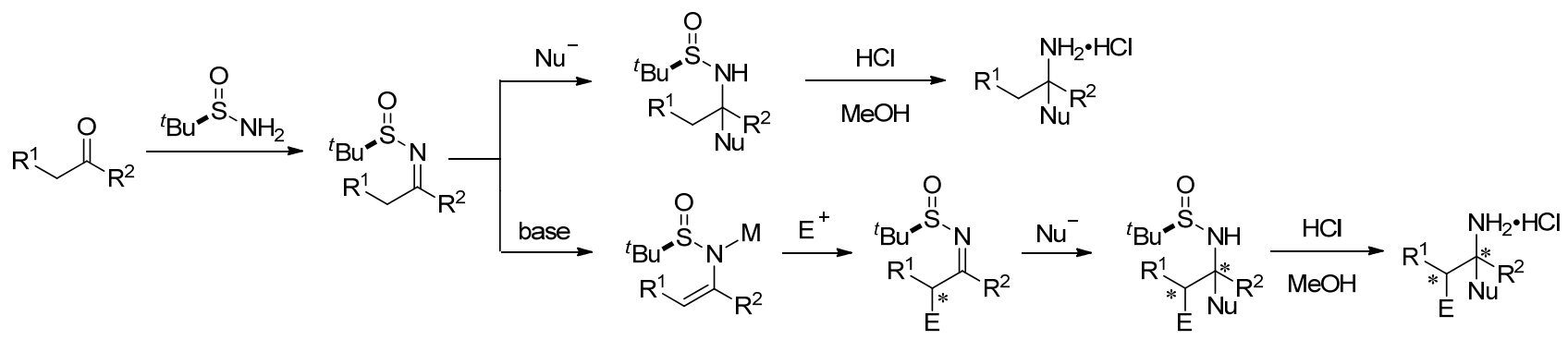

图式 1 叔丁基亚磺酰胺诱导手性胺的合成

Scheme 1 Synthesis of chiral amines using tert-butanesulfinamide

\section{1 叔丁基亚磺酰亚胺的 1,2-加成反应}

叔丁基亚磺酰亚胺在多种亲核加成反应中都有应 用, 在此分为三部分介绍: 叔丁基亚磺酰亚胺与亲核试 剂的 1,2-加成反应、叔丁基亚磺酰亚胺的还原和 $\mathrm{SmI}_{2}$ 促进的叔丁基亚磺酰亚胺的还原偶联反应.

\section{1 叔丁基亚磺酰亚胺与亲核试剂的 1,2-加成反应}

由于叔丁基亚磺酰基的吸电子效应, 叔丁基亚磺酰 亚胺表现出较强的亲电性, 可与多种亲核试剂发生 1,2加成反应. 此外, 化学家还发展了金属催化的叔丁基亚 磺酰亚胺的加成反应. 根据叔丁基亚磺酰亚胺与不同的 亲核试剂发生 1,2-加成反应, 在天然产物全合成中的应 用进行介绍, 主要分为四部分: 包括叔丁基亚磺酰亚胺 与格氏试剂的 1,2-加成反应、叔丁基亚磺酰亚胺与有机 锂试剂的,2-加成反应、金属催化的 1,2-加成反应以及与 其他碳负离子的 1,2-加成反应.

\subsection{1 叔丁基亚磺酰亚胺与格氏试剂的 1,2-加成反应}

2006 年, Rozwadowska 课题组 ${ }^{[5]}$ 报道了 $(S)-(-)-$ salsolidine 的全合成. 他们利用叔丁基亚磺酰亚胺与格 氏试剂发生立体选择性的 1,2-加成反应, 成功引入分子 内唯一的手性中心.

3,4-二甲氧基苯甲醛 (1) 与 $(R)$-叔丁基亚磺酰胺在 $\mathrm{Ti}\left(\mathrm{O}^{i} \mathrm{Pr}\right)_{4}$ 作用下缩合生成叔丁基亚磺酰亚胺 2, 随后与 甲基溴化镁发生加成反应, 以高收率和立体选择性得到 化合物 $3, d r$ 值为 $98: 2$. 化合物 3 在盐酸作用下脱除叔 丁基亚磺酰基后, 与溴代乙醛缩二乙醇(4)发生氮烷基 化反应得到化合物 5. 最后在酸性条件下发生分子内的 傅克羟烷基化反应, 生成的环化产物在 $\mathrm{NaBH}_{4}$ 和三氟 醋酸(TFA)作用下脱氧得到 $(S)-(-)$-salsolidine, ee 值为 98\% (Scheme 2).

该课题组通过线性 5 步转化, 并以 $24 \%$ 的总收率和 $98 \%$ 的 $e e$ 值合成了 $(S)-(-)$-salsolidine. 该策略丰富了合 成异喹啉骨架的方法, 同时也可以用于合成一些 1,2,3,4-四氢咔啉(THBC)生物碱.

2015 年, 林国强课题组 ${ }^{[6]}$ 发展了一种高效不对称合

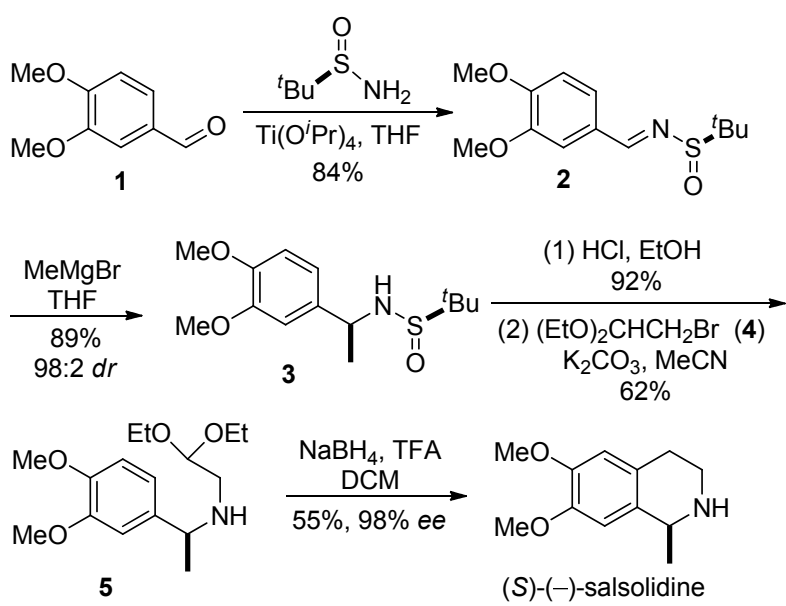

图式 2 Rozwadowska 课题组关于 $(S)-(-)$-salsolidine 的合成 Scheme 2 Synthesis of $(S)-(-)$-salsolidine by Rozwadowska group

成反式-5-差基-6-烯基/炔基-2-哌啶酮的方法，并用该方 法实现了 $(+)$-swainsonine 的合成. 采用的关键策略是手 性叔丁基亚磺酰亚胺与炔基格氏试剂的 1,2-加成反应.

起始物 6 先后与乙炔溴化镁和 $\mathrm{Boc}_{2} \mathrm{O}$ 反应, 两步一 锅法制备得到哌啶酮化合物 7. 在 Lindlar 催化剂催化下 将 7 结构中的炔键氢化同时脱除Boc 保护基, 生成的产 物与烯丙基溴发生氮烷基化反应得到双烯化合物 8. 在 第二代 Grubbs 催化剂的催化下化合物 8 发生关环复分 解(RCM)反应, 构建五元环, 得到双环化合物 9 . 化合物 9 发生立体选择性的双羟化反应生成二醇化合物 10. 最 后化合物 10 经过 $\mathrm{LiAlH}_{4}$ 还原和脱除叔丁基二甲基硅烷 基(TBS)即可得到 $(+)$-swainsonine. 此外，林国强课题 组 ${ }^{[7]}$ 应用该策略还合成了 streptopyrrolidine (Scheme 3).

该课题组开发的合成反式-5-羟基-6-烯基/炔基-2-哌 啶酮的方法具有较好的立体选择性, 并且多种类型的格 氏试剂均适用于此反应. 该方法具有应用于更多复杂化 生物碱合成的潜力.

2016 年, Love 课题组 ${ }^{[8]}$ 利用叔丁基亚磺酰亚胺的立 体选择性加成制备了关键手性炔丙基胺中间体，继而完 成了 K777 的合成. 
<smiles></smiles>

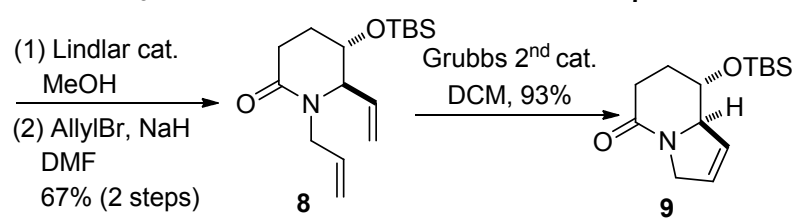

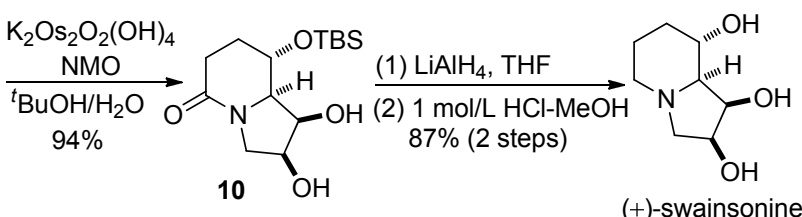<smiles></smiles>

图式 3 林国强课题组关于 (+)-swainsonine 的全合成

Scheme 3 Total synthesis of $(+)$-swainsonine by Lin group

以苯丙醛 11 为起始物，与(S)-叔丁基亚磺酰胺在 $\mathrm{KHSO}_{4}$ 作用下缩合得到叔丁基亚磺酰亚胺 $\mathbf{1 2}$. 亚胺 $\mathbf{1 2}$ 与炔基格氏试剂 13 发生不对称的加成反应生成 14, 再 经过 4 步保护基转化得到炔丙基胺 15. 在 Wilkinson 催 化剂作用下, 苯硫酚与炔烃 15 加成得到乙烯基硫化物 16, 16 经过 $m$-CPBA 氧化为砜基化合物 17. 在 TFA 作用 下化合物 17 脱除 Boc 保护基, 最后与手性酸 18 发生缩 合得到 K777 (Scheme 4).

作者使用叔丁基亚磺酰亚胺合成 $\mathrm{K} 777$, 避免了使 用昂贵的 $L$-苯基丁氨酸作为起始原料, 提高了合成的经 济性.

2017 年, Amat 课题组 ${ }^{[9]}$ 发展了一种合成 5,7-顺式二 取代十氢喹啉的方法, 并应用该方法合成了天然产物 (一)-cermizine B. 作者通过叔丁基亚磺酰亚胺与烯丙基 格氏试剂的不对称 1,2-加成反应，构建了一个氮杂手性 中心.

在 $\mathrm{InCl}_{3}$ 催化作用下, 烯酮 19 和烯丙基硅 20 发生 Sakurai 反应生成化合物 21. 化合物 21 和 $(R)$-苯基甘氨 醇在酸性条件下缩合生成单一的三环顺式稠合内酰胺 22, 随后经过三氯化钉催化的氧化切断, 生成的醛基化 合物与 $(R)$-叔丁基亚磺酰胺缩合得到叔丁基亚磺酰亚胺 23. 烯丙基溴化镁与亚胺 23 发生高立体选择性的加成 反应，立体专一性地得到加成产物 24. 化合物 24 脱去 叔丁基亚磺酰基后，与丙烯酰氯 25 发生酰胺化反应生 成双烯化合物 26. 化合物 $\mathbf{2 6}$ 经过 RCM 反应得到二氢吡 啶酮衍生物 27, 最后经过 4 步转化完成对氧化态的调
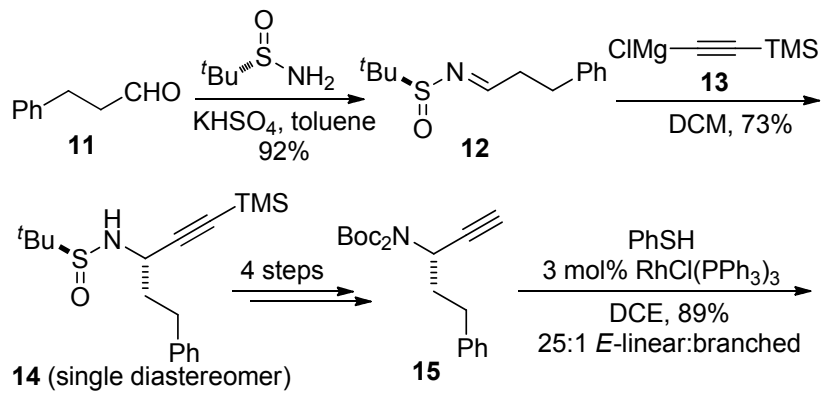

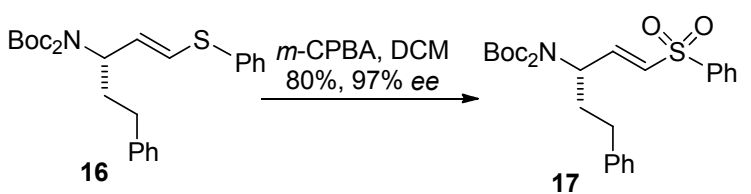

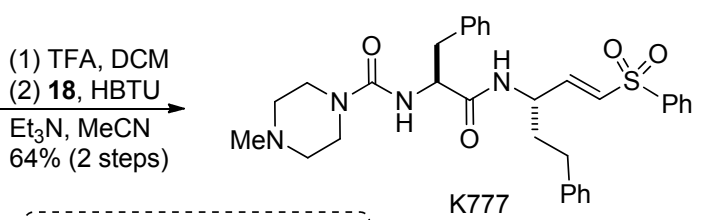<smiles>CN1CCN(C(=O)NC(CO)C(=O)O)CC1</smiles>

图式 4 Love 课题组关于 K777 的全合成

Scheme 4 Total synthesis of K777 by Love group

整，可以得到天然产物(一)-cermizine B. 该课题组 ${ }^{[10]}$ 应 用同样的策略合成了 $(+)$-serratezomine $\mathrm{E}$ 和 $(+)$-luciduline (Scheme 5).

Amat 课题组应用叔丁基亚磺酰亚胺的高立体选择 性 1,2-加成反应和 RCM 反应高效实现了手性哌啶环的 构建. 该策略丰富了包含手性哌啶环天然产物的合成方 法.

2018 年, Taghizadeh 课题组 ${ }^{[11]}$ 以 $(S)$-叔丁基亚磺酰 胺作为手性辅基引入 $(S)$-ketamine 结构中唯一的手性中 心, 继而完成了 $(S)$-ketamine 的合成.

用乙二醇对 1,2-环已二酮 $\mathbf{2 8}$ 进行单保护，与(S)-叔 丁基亚磺酰胺缩合生成叔丁基亚磺酰亚胺 30. 接下来 2-氯苯基溴化镁 31 和叔丁基亚磺酰亚胺 30 发生高立体 选择性的 1,2-加成反应构建氮杂季碳手性中心, 得到化 合物 32, $d r$ 值为 $9: 1$. 最后通过 2 步脱保护转化实现了 $(S)$-ketamine 的合成 (Scheme 6).

Taghizadeh 课题组报道的通过芳基格式试剂对叔丁 基亚磺酰亚胺的加成，构建手性芐胺的策略，拓展了茮 位手性季碳中心的构建方法.

应用叔丁基亚磺酰亚胺与格氏试剂的 1,2-加成反应 作为关键合成策略完成的分子还有 Pozo 课题组 ${ }^{[12 a]}$ 合成 的(一)-pinidinol、张洪涁课题组 ${ }^{[12 b]}$ 合成的 $(+)$-nocardioazine B、Prasad 课题组 ${ }^{[12 c]}$ 合成的 lentiginosine 和 


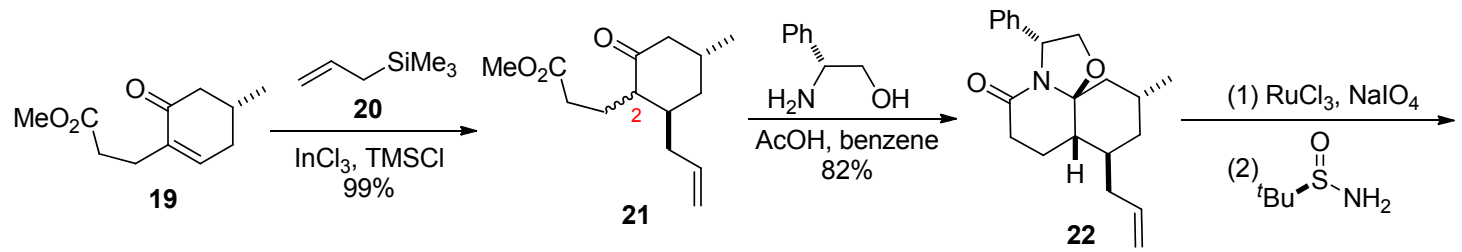

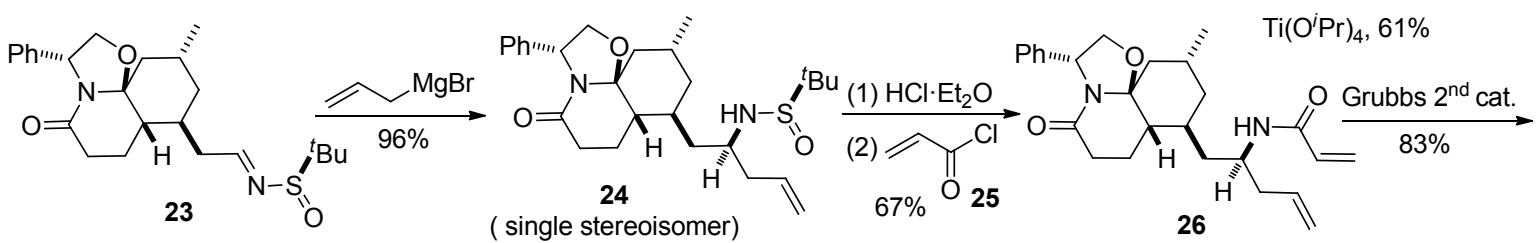<smiles>C[C@@H]1CC(C[C@H]2CC=CC(=O)N2)[C@@]23CCC(=O)N2C(c2ccccc2)CO[C@@]13C</smiles>

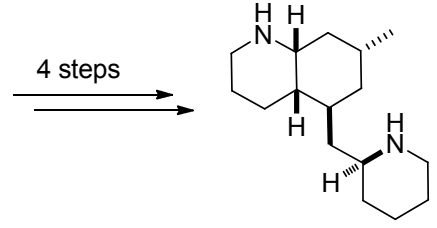

(-)-cermizine B

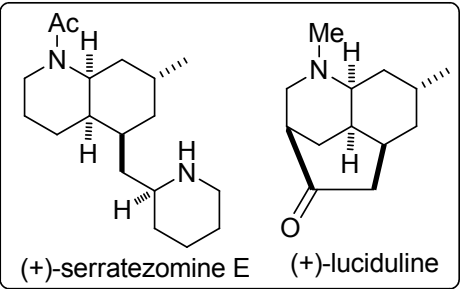

图式 5 Amat 课题组关于(一)-cermizine B 的全合成

Scheme 5 Total synthesis of (-)-cermizine B by Amat group

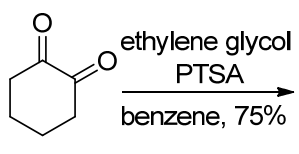

28

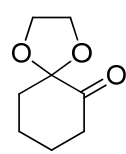

29

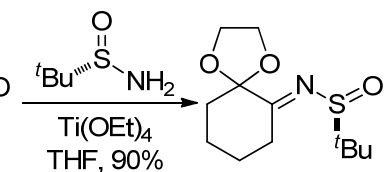

30

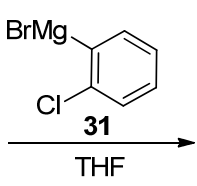

$85 \%, 9: 1 d r$

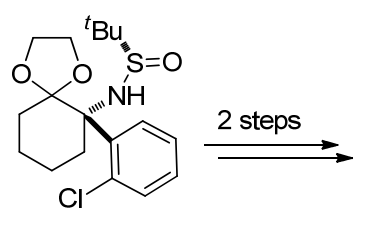

32

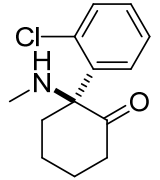

(S)-ketamine
图式 6 Taghizadeh 课题组关于 $(S)$-ketamine 的全合成 Scheme 6 Total synthesis of $(S)$-ketamine by Taghizadeh group Methyldihydropalustramate 以及 Muñiz 课题组 ${ }^{[12 d]}$ 合成的 nicotine.

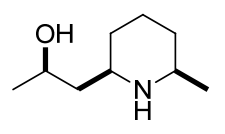

(-)-pinidinol

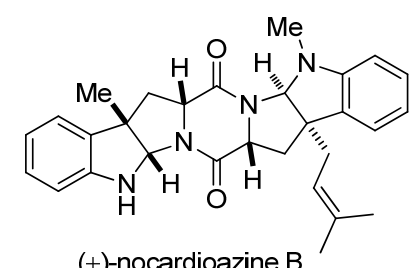

(+)-nocardioazine B<smiles>OC1[C@@H](O)CN2CCCC[C@@H]12</smiles>

lentiginosine<smiles>CCC(O)[C@@H]1CCC[C@@H](CC(C)=O)N1</smiles>

(-)-methyldihydropalustramate

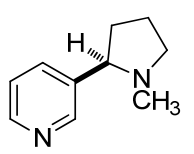

nicotine
1.1.2 叔丁基亚磺酰亚胺与有机锂试剂的 1,2-加成反 应

2011 年, Reisman 课题组 ${ }^{[13]}$ 报道了手性苯醌单缩酮 亚磺酰亚胺的制备方法, 并将其应用到天然产物(一)-3- demethoxyerythratidinone 的全合成中. 采用的关键策略 是手性叔丁基亚磺酰亚胺与金属有机物发生高立体选 择性 1,2-加成反应引入氮杂螺环立体中心.

苯醌单缩酮 33 与 $(R)$-叔丁基亚磺酰胺缩合得到叔 丁基亚磺酰亚胺 34. 亚胺 34 与芳基锂发生高立体选择 性的 1,2-加成, 经过一锅法分子内氮烷基化引入螺环手 性中心, 得到化合物 36, $d r$ 值为 $98: 2$. 化合物 36 与锡 试剂 37 在零价钯促进下发生 Stille 偶联反应，在酸作用 下脱除叔丁基亚磺酰基，氨基与烯醇醚在酸性条件下发 生缩合形成氮杂五元环, 生成化合物 38. 最终还原 38 生成(一)-3-demethoxyerythratidinone (Scheme 7).

Reisman 课题组发展了手性苯醌单缩酮亚磺酰亚胺 与金属有机化合物的加成反应，构建了 4-氨基环己二烯 酮的季碳手性中心, 利用该方法高效地实现了(一)-3-demethoxyerythratidinone 的螺环手性中心的构建, 并最终 以 6 步 26\%的收率完成了(-)-3-demethoxyerythratidinone 的合成. 此方法为合成含有 4-氨基环已二烯酮片 段的天然产物提供了新思路.

2017 年, Morris 课题组 ${ }^{[14]}$ 报道了萗基异喹啉类生物 碱 dioncophylline $\mathrm{E}$ 的全合成. 其核心策略是芳基三乙 酸铅与萗酚通过 Pinhey-Barton ortho-arylation 反应连接. 通过对叔丁基亚磺酰亚胺的高立体选择性加成反应引 入 C(3)位手性中心，同时引入构建异喹啉环所需的氮原 子.

作者从苯酚化合物 39 出发, 经过 4 步转化得到芳基 三乙酸铅 $\mathbf{4 0}$, 再与菜酚 41 发生偶联反应得到联芳化合 物 42. 接下来需要构建异喹啉环, 化合物 $\mathbf{4 2}$ 经 $\mathrm{Bn}$ 保护 
<smiles>COC1(OC)C=CC(=O)C(Br)=C1Br</smiles>

33<smiles>COc1cc2c(cc1OC)[C@@]1(CCC(OC)(OC)C=C1Br)N(S(=O)CC(C)C)CC2</smiles>
$\mathrm{MeO} \mathrm{OMe}$

36<smiles>CCN1C=CC2(C=CC(=O)C=C2)c2cc(OC)c(OC)cc21</smiles>

38

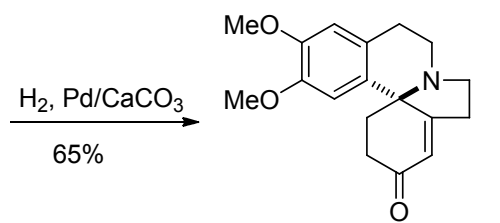

(-)-3-demethoxyerythratidinone

图式 7 Reisman 课题组关于(-)-3-demethoxyerythratidinone 的 全合成

Scheme 7 Total synthesis of ( - )-3-demethoxyerythratidinone by Reisman group

后, 其结构中的甲基在二异丙基氨基锂(LDA)条件下去 质子化生成碳负离子, 与亚胺 43 发生高立体选择性的 加成反应生成化合物 44, $d r$ 值为 $97: 3$. 化合物 44 用二 异丁基氢化铝(DIBAL-H)还原后, 在盐酸作用下脱除叔 丁基亚磺酰基，生成的胺基与醛基缩合构建异喹啉 45 . 在 $\mathrm{MeLi}$ 和 $\mathrm{CeCl}_{3}$ 存在条件下 ${ }^{[15]}$, 亚胺 $\mathbf{4 5}$ 发生立体选择 性的亲核加成反应构建 $\mathrm{C}(1)$ 位手性中心, $d r$ 值大于 97 : 3 , 最后在 $\mathrm{BCl}_{3}$ 条件下脱除 $\mathrm{Bn}$ 保护基, TFA 酸化合成 dioncophylline E•TFA (Scheme 8).

Morris 课题组报道的手性叔丁基亚磺酰亚胺与苄 基负离子发生不对称加成反应，高效地构建 1,3-二取 代四氢异喹啉中的两个手性中心.

2019 年, Prasad 课题组 ${ }^{[16]}$ 报道了手性叔丁基亚磺酰 亚胺与二苯基烯丙基亚胺负离子发生高立体选择性的 加成反应, 生成手性的 1,2-二胺基化合物. 他们利用该 方法经过 6 步转化完成了(一)-epiquinamide 的合成.

二苯基烯丙基亚胺 47 在 ${ }^{n} \mathrm{BuLi}$ 作用下发生去质子 化形成碳负离子, 再与 5-溴戊醛衍生的叔丁基亚磺酰亚 胺 46 发生高立体选择性的加成反应, 引入 (一)-epiquinamide 结构中的两个立体中心. 在 $\mathrm{NaH}$ 作用下发生分子 内 $\mathrm{S}_{\mathrm{N}} 2$ 反应得到哌啶化合物 48, $d r$ 值为 $96: 4$. 化合物 48 经过 4 步官能团转化生成双烯化合物 49, 经过 RCM 反应构建二氢哌啶环, 最后还原双键实现了天然产物的 (一)-epiquinamide 的合成(Scheme 9).

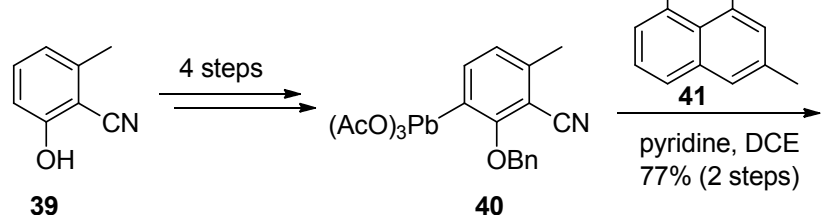

39

(1) $\mathrm{NaH}, \mathrm{DMF}$

then $\mathrm{BnBr}, 87 \%$

(2) LDA, THF, then<smiles>COc1cccc2cc(C)c(-c3ccc(C)c(COc4ccccc4)c3O)c(O)c12</smiles>

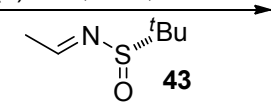

$72 \%,>97: 3 d r$

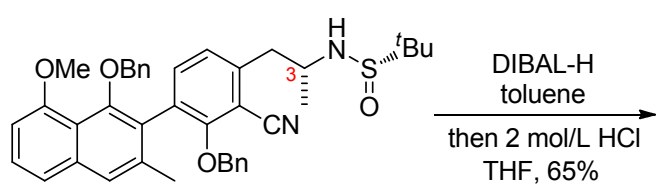

44

(1) $\mathrm{MeLi}, \mathrm{CeCl}_{3}$ THF, $75 \%$

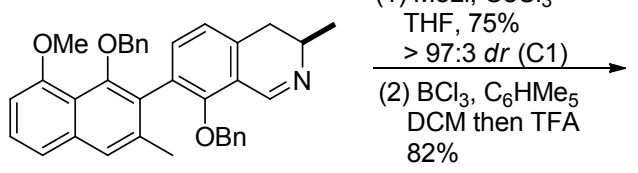

45<smiles>COc1cccc2cc(C)c(-c3ccc4c(c3O)C(C)=N[C@@H](C)C4)c(O)c12</smiles>

dioncophylline E•TFA OTFA

图式 8 Morris 课题组关于 dioncophylline E•TFA 的全合成 Scheme 8 Total synthesis of dioncophylline E•TFA by Morris group

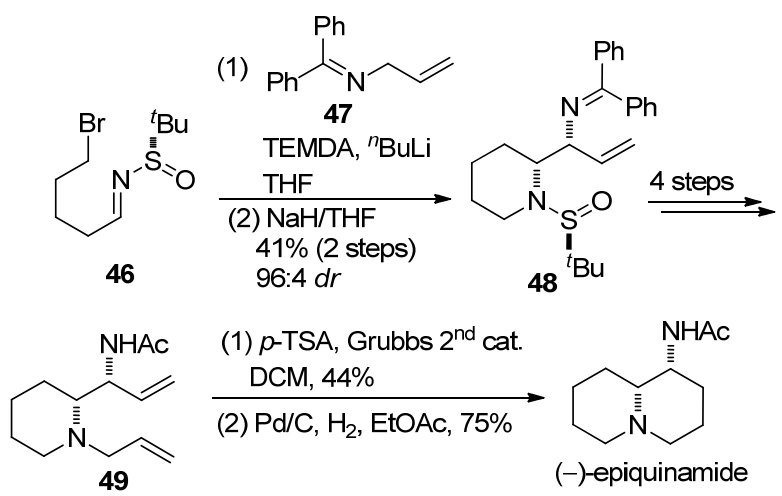

图式 9 Prasad 课题组关于(一)-epiquinamide 的全合成 Scheme 9 Total synthesis of (-)-epiquinamide by Prasad group

作者报道的手性叔丁基亚磺酰亚胺与 2-氮杂烯丙 基负离子的不对称加成反应，可以构建 1,2-二胺基中间 体, 为合成包含 1,2-二胺基特征结构的生物碱提供了引 入手性中心的方法.

2006 年, 秦勇课题组 ${ }^{[17]}$ 报道了保护的羟基乙酸酯 与叔丁基亚磺酰亚胺的加成反应，并应用该方法实现了 
$\beta$-内酰胺型紫杉醇侧链前体的合成.

在双(三甲基硅基)胺基锂(LiHMDS)作用下, Boc 保 护的羟基乙酸茮酯 50 首先生成烯醇负离子, 然后与叔 丁基亚磺酰亚胺 $\mathbf{5 1}$ 发生高立体择性的 Mannich 反应，引 入两个连续立体中心, 得到化合物 52, ee 值高达 99\%. 在 Pearlman 催化剂催化下氢解酯 $\mathbf{5 2}$ 可制得直链型紫杉 醇侧链前体 53, 再经过分子内缩合得到光学纯的 $\beta$-内 酰胺型紫杉醇侧链前体 54. 环丁酰胺 54 可以用于紫杉 醇的半合成(Scheme 10).
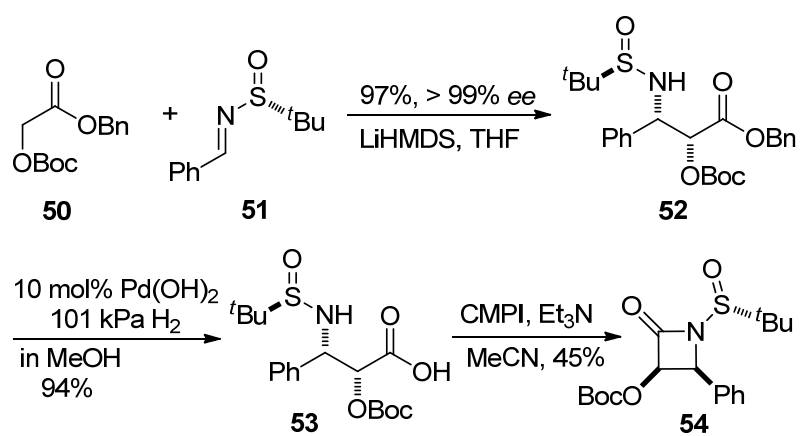

图式 10 秦勇课题组关于紫杉醇侧链前体的全合成

Scheme 10 Total synthesis of taxol side chain by Qin group

作者发展的叔丁基亚磺酰亚胺的高立体选择性 1,2加成反应可以高效地合成紫杉醇侧链前体，可应用于紫 杉醇衍生物的合成.

2015 年, Njardarson 课题组 ${ }^{[18]}$ 报道了一种基于叔丁 基亚磺酰亚胺的不对称 $[3+2]$ 环化反应构建 3-吡咯啉的 新方法, 并应用该方法实现了 $(-)$-supinidine, ( - )-isoretronecanol 和 $(+)$-elacomine 的简洁合成.

他们以醛 55 作为原料, 与 $(S)$-叔丁基亚磺酰胺在 $\mathrm{Ti}\left(\mathrm{O}^{i} \mathrm{Pr}\right)_{4}$ 作用下缩合生成叔丁基亚磺酰亚胺 56. 4-溴巴 豆酸乙酯(57)在 LDA 作用下去质子化生成的碳负离子 与亚胺 56 发生 1,2-加成反应后, 生成氮负离子中间体发 生 $\mathrm{S}_{\mathrm{N}} 2$ 反应，经过 5-exo-tet 环化生成 3-吡咯啉化合物 58. 化合物 58 在新制备的 $\mathrm{HCl}$ 作用下脱除叔丁基亚磺酰基 后, 在 $\mathrm{Et}_{3} \mathrm{~N}$ 作用下发生分子内 $\mathrm{S}_{\mathrm{N}} 2$ 反应构建吡咯环, 以 DIBAL-H 作为还原剂, 还原酯基实现了(一)-supinidine 的合成. 在 $\mathrm{Pd} / \mathrm{C}$ 和 $\mathrm{H}_{2}$ 条件下, (一)-supinidine 发生立体 选择性还原, 得到(-)-isoretronecanol. 另外, 叔丁基亚 磺酰亚胺 59 与 4-溴巴豆酸乙酯(57)在 LDA 作用下发生 不对称的 $[3+2]$ 环化反应生成 3-吡咯啉化合物 60, 再与 芳香胺 61 发生胺解得到碘代芳基酰胺 62 . 化合物 62 在 零价钯促进下发生分子内 Heck 环化反应, 构建季碳手 性中心, 生成螺环氧化吲哚 63. 化合物 63 在锌粉及冰 醋酸条件下脱除叔丁基亚磺酰基, 同时还原生成的亚胺 后, 再在 $\mathrm{BBr}_{3}$ 条件下脱除甲基可以实现天然产物 (十)-elacomine 的合成(Scheme 11).
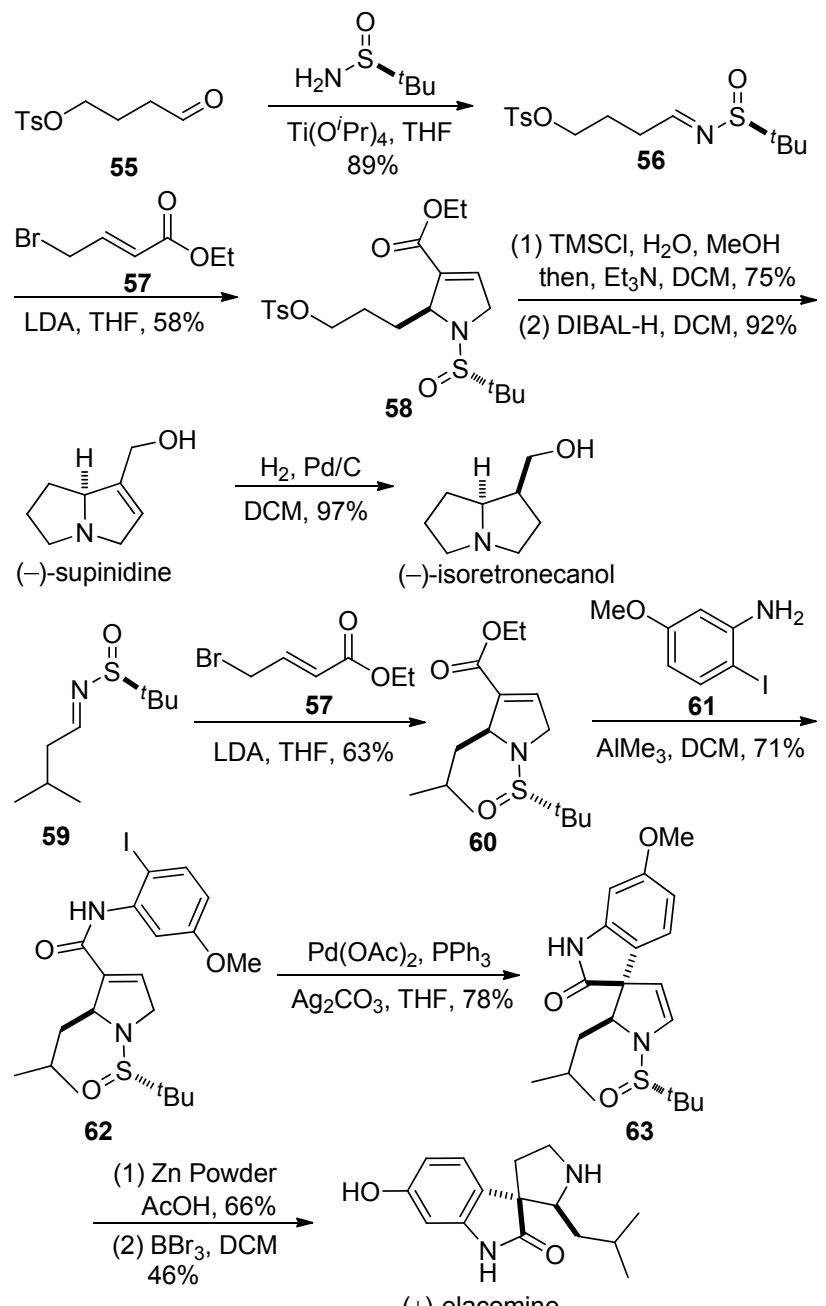

(+)-elacomine

图式 11 Njardarson 课题组关于(一)-supinidine, (一)-isoretronecanol 和 $(+)$-elacomine 的全合成

Scheme 11 Total synthesis of $(-)$-supinidine, ( -$)$-isoretronecanol and $(+)$-elacomine by Njardarson group

Njardarson 课题组发展的不对称 $[3+2]$ 环化反应构 建 3-吡咯啉的新方法, 丰富了叔丁基亚磺酰亚胺在构建 杂环化合中的应用，拓展了杂环上的手性取代基构建的 方法.

2017 年, 张洪涁课题组 ${ }^{[19]}$ 发展了吲哚取代的叔丁 基亚磺酰亚胺与二氧杂环己酩之间的选择性 vinylogous Mannich 反应, 并以该反应作为关键步骤完成了 $(-)$ vindorosine 的不对称全合成. 他们通过 vinylogous Mannich 反应引入 C(19)位和 C(5)位两个手性中心，其 中 C(19)位手性中心在串联 Heathcock/aza-Prins 环化反 应中诱导 C(12)位手性中心的生成.

他们以醛 64 与 $(S)$-叔丁基亚磺酰胺为原料, 发生缩 合生成叔丁基亚磺酰亚胺 65 . 在 LiHMDS 作用下, dioxinone 66 生成的烯醇负离子与亚胺 65 发生 vinylogous Mannich 反应，引入 C(19)位和 C(5)位两个立 
体中心, 生成化合物 67 和 $68, d r$ 值为 $7.6: 1$. 在 $\mathrm{I}_{2}$ 条件

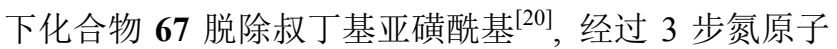
上的官能团转化得到化合物 70. 化合物 70 在 $\mathrm{NaI}$ 条件 下发生卤素交换后, 在 $\operatorname{Ag}(\mathrm{OTf})_{2}$ 作用下发生分子内串 联 Heathcock/aza-Prins 环化反应构建 $\mathrm{C}$ 和 $\mathrm{E}$ 两个环，同 时引入 $\mathrm{C}(12)$ 位和 $\mathrm{C}(2)$ 位的手性中心, 生成四环化合物 71. 化合物 71 经过氧化切断端烯和吲哚氮上引入保护 基得到 72, 在 1,5-二氮杂二环 [5.4.0]十一烯-5 (DBU)条 件下发生分子内 aldol 反应构建 $\mathrm{D}$ 环, 引入 C(6)位手性 中心得到五环骨架化合物 73. 化合物 73 经过 3 步转化 得到 74, 经过 Luche 还原 C(4)位得到预期外的单一异构 体醇 75. 利用 Mitsunobu 反应将化合物 75 的 C(4)位手 性异构 ${ }^{[21]}$ 后, 经过 $m$-CPBA 氧化烯胺引入 $\mathrm{C}(3)$ 位羟 基 ${ }^{[22]}$, 还原胺化引入吲哚氮原子上的甲基取代基, 得到 化合物 76. 最后经过 2 步还原及酯化反应完成了 (一)-vindorosine 的合成(Scheme 12).

张洪涁课题组开发的基于吲哚取代的叔丁基亚磺 酰亚胺的克级 vinylogous Mannich 反应, 在吲哚 3 位引 入手性边链进行修饰后, 通过串联 Heathcock/aza-
Prins 环化反应，高效构建了 $\mathrm{C}$ 和 $\mathrm{E}$ 两个环得到化合物 71.71 作为关键中间体可用于合成其他吲哚生物碱.

2017 年, Brown 课题组 ${ }^{[23]}$ 以叔丁基亚磺酰亚胺和戊 二酸衍生物的双 imino-aldol 反应为关键步骤, 经过线性 5 步完成了 $(+)-\beta$-isosparteine 不对称合成.

戊二酸酯 77 在 LDA 作用下形成双烯醇负离子, 与 2 equiv.的叔丁基亚磺酰亚胺 78 发生双 imino-aldol 反 应 ${ }^{[24]}$ 一步生成 4 个立体中心，得到预期的化合物 79b 以 及副产物 79a. 化合物 79b 在 $I_{2}$ 作用下脱去叔丁基亚磺 酰基后，在 $\mathrm{Na}_{2} \mathrm{CO}_{3}$ 作用下发生酰胺化反应，生成化合 物 80. 在 $\mathrm{KOH}$ 条件下化合物 80 发生分子内双 $\mathrm{S}_{\mathrm{N}} 2$ 反应 构建 2 个哌啶环，最后还原酰胺合成 $(+)-\beta$-isosparteine. 此外, Brown 课题组 ${ }^{[25]}$ 应用 imino-aldol 反应还合成了 $(-)$-tashiromine, $(-)$-epilupinine 和 $(+)$-allomatrine (Scheme 13).

Brown 课题组利用叔丁基亚磺酰亚胺的双 iminoaldol 反应可以高效地在链状底物中构建多个手性中心, 增加了手性链状化合物的合成方法.

应用叔丁基亚磺酰亚胺与有机锂试剂的 1,2-加成反<smiles>CC(C)(C)OC(=O)n1cc(C=O)c2ccccc21</smiles>

64

Boc

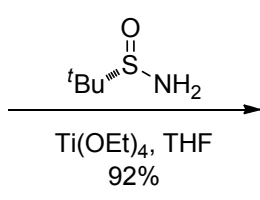

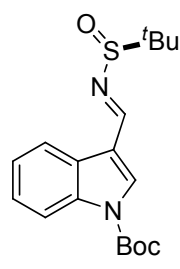

65

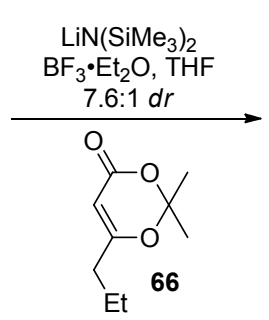

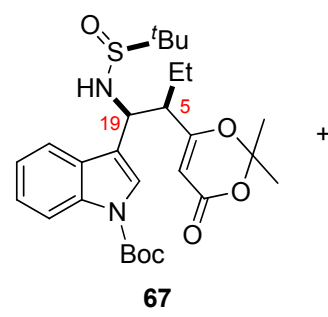

67<smiles>CCC(C)S(=O)N[C@H](c1cn(C(=O)OC(C)(C)C)c2ccccc12)[C@H](CC)C1=CC(=O)OC(C)(C)O1</smiles>

68

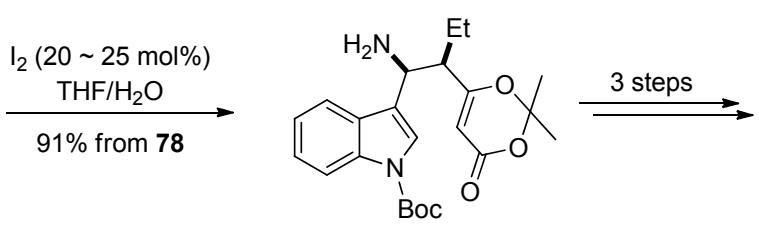

69

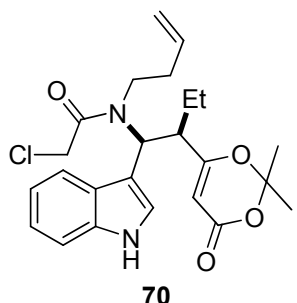

70
(1) Nal, acetone

(2) AgOTf, THF $83 \%$, overall

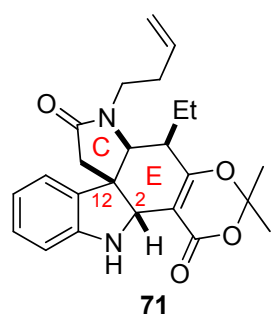

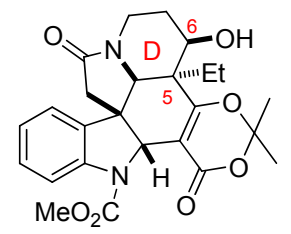

73

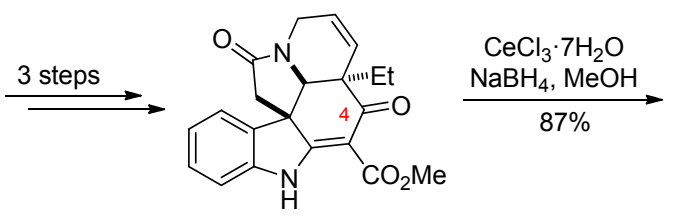

74

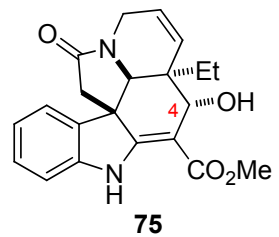

(1) $\mathrm{CBr}_{4}, \mathrm{PPh}_{3}$; toluene then THF, $\mathrm{H}_{2} \mathrm{O}, \mathrm{NaHCO}_{3}, 81 \%$

(2) $m \mathrm{CPBA}, \mathrm{DCM} / \mathrm{MeOH}$, then $\mathrm{HCHO}$, $\mathrm{NaBH}_{3} \mathrm{CN}, 60 \%$
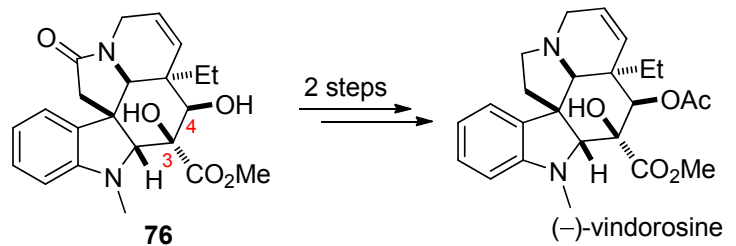

图式 12 张洪涁课题组关于(一)-vindorosine 的全合成

Scheme 12 Total synthesis of ( - )-vindorosine by Zhang and co-workers 


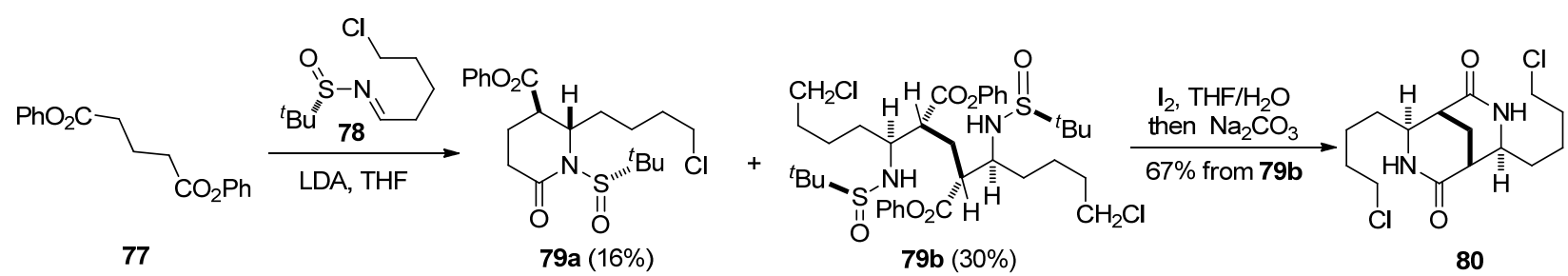

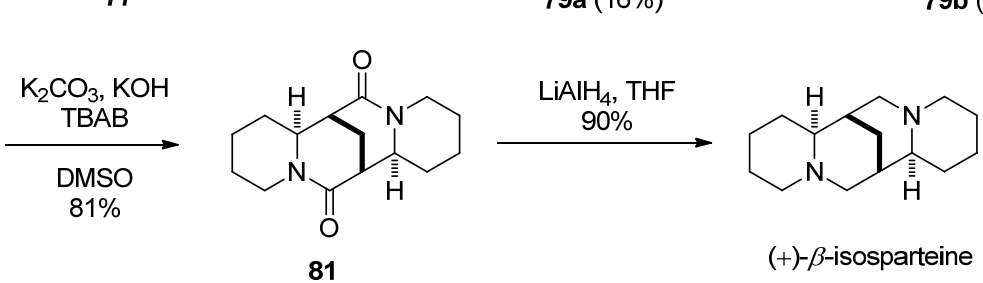

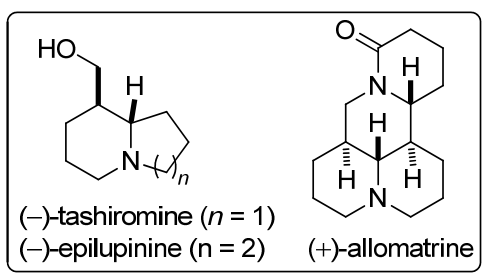

图式 13 Brown 课题组关于 $(+)-\beta$-isosparteine 的全合成

Scheme 13 Total synthesis of $(+)-\beta$-isosparteine by Brown group

应作为关键合成策略完成的分子还有 Senanayake 课题 组 ${ }^{[26 a]}$ 合成的 $(R)$-sibutramine、Baran 课题组 ${ }^{[26 b]}$ 合成的 $(+)$-araiosamine C、魏邦国课题组 ${ }^{[26 c]}$ 合成的 $(+)-$ halofuginone 以及 Sarpong 课题组 ${ }^{[26 \mathrm{~d}]}$ 合成的 $(-)$-daphlongamine $\mathrm{H}$ 和( - )-isodaphlongamine $\mathrm{H}$.<smiles>CC(C)CC(N(C)C)C1(c2ccc(Cl)cc2)CCC1</smiles>

$(R)$-sibutramine

(+)-halofuginone

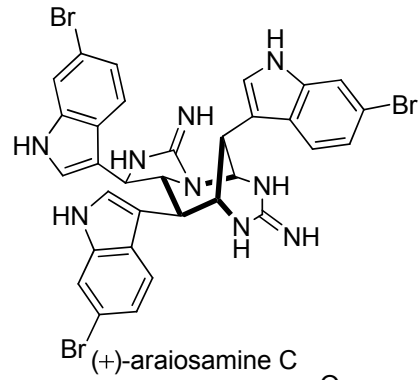

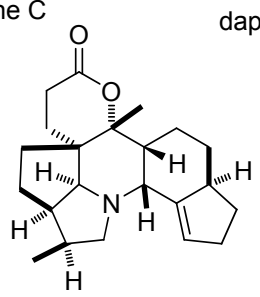

1.1.3 过渡金属催化的叔丁基亚磺酰亚胺的 1,2-加成 反应

2010 年, Ellman 课题组 ${ }^{[27]}$ 报道了 $($ - )-aurantioclavine 的不对称全合成. 合成中以 $\mathrm{Rh}(\mathrm{I})$ 催化的叔丁基 亚磺酰亚胺的高立体选择性 1,2-加成反应为关键步引入 (一)-aurantioclavine 结构中唯一的立体中心.

作者从 4-溴色醇 $(82)$ 出发, 吲哚 C(4)位发生甲酰化 反应得到醛 83,83 与 $(R)$-叔丁基亚磺酰胺缩合得到叔丁

基亚磺酰亚胺 84, 再经过吲哚和一级差基的保护得到 化合物 85 . 亚胺 85 和 $N$-甲基亚氨基二乙酸喼酸酯 86 在 $\mathrm{Rh}(\mathrm{I})$ 催化下，发生不对称的烯基化反应生成化合物 87, 反应取得非常好的立体选择性, $d r$ 值为 $97: 3$. 化合 物 87 在 $\mathrm{NaH}$ 条件下发生分子内 $\mathrm{S}_{\mathrm{N}} 2$ 反应构建氮杂环庚 烷, 再经过 2 步脱保护得到 $e e$ 值大于 $99 \%$ 的 (一)aurantioclavine (Scheme 14).

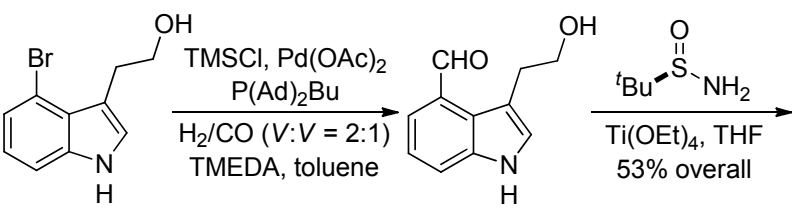

82<smiles>CC(C)(C)[S@](=O)/N=C/c1cccc2[nH]cc(CCO)c12</smiles>

84

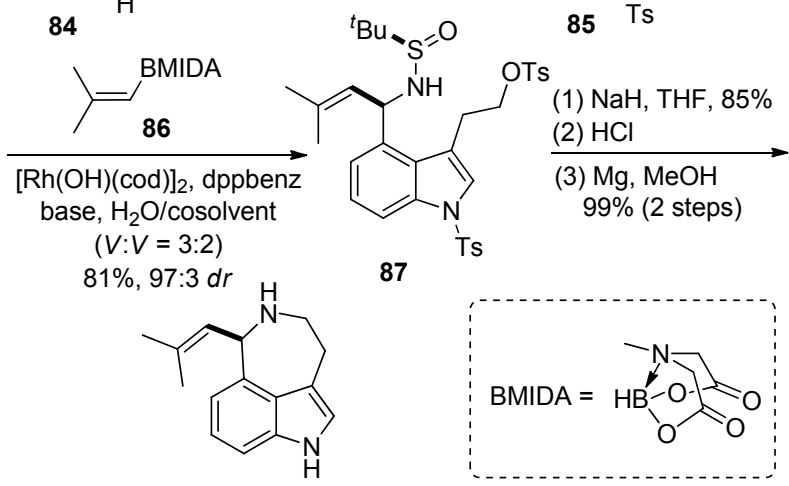

$(-)$-aurantioclavine $(>99 \%$ ee)

图式 14 Ellman 课题组关于(一)-aurantioclavine 的全合成 Scheme 14 Total synthesis of (-)-aurantioclavine by Ellman group

作者发展的 $\mathrm{Rh}(\mathrm{I})$ 催化的叔丁基亚磺酰亚胺的不对 
称烯基化反应，丰富了叔丁基亚磺酰亚胺的加成反应类 型.

2017 年, 孙兴文课题组 ${ }^{[28]}$ 发展了钯催化的手性叔 丁基亚磺酰亚胺的高立体选择性 1,2-加成反应, 可以合 成手性纯的 $\beta$-芳基高烯丙基胺，并利用该方法引入 $\mathrm{C}(4 \mathrm{a})$ 位和 $\mathrm{C}(10 \mathrm{a})$ 位两个立体中心, 成功实现了 $(+)$-lycori- cidine 和 $(+)$-7-deoxypancratistatin 的全合成.

他们以碘代核糖衍生物 88 为原料，与 ${ }^{n} \mathrm{BuLi}$ 作用发 生消除后，与 $(S)$-叔丁基亚磺酰胺缩合得到叔丁基亚磺 酰胺亚胺 89. 接下来在 $\mathrm{Pd}\left(\mathrm{PPh}_{3}\right)_{4}$ 和 $\mathrm{ZnEt}_{2}$ 条件下, 亚胺 89 和醋酸肉桂醇酯衍生物 90 发生串联的不对称 1,2-加 成反应及分子内的胺解反应，构建了 $\mathrm{B}$ 环，引入了 $\mathrm{C}(4 \mathrm{a})$ 位和 $\mathrm{C}(10 \mathrm{a})$ 位两个立体中心, 得到单一异构体 91 . 化合物 91 通过 RCM 反应构建 $\mathrm{C}$ 环得到化合物 92 后, 再 经过双着化和脱叔丁基亚磺酰基生成二醇 93. $\mathrm{SOCl}_{2}$ 与 二醇 93 反应生成环状亚砜化合物, 接着在 $\mathrm{RuCl}_{3}$ 和 $\mathrm{NaIO}_{4}$ 条件下氧化得到环硫酸酯 94.94 在 ${ }^{n} \mathrm{Bu}_{4} \mathrm{NI}$ 的作用 下, 在位阻小的 $\mathrm{C}(1)$ 位发生开环生成碘代物, 再在酸性 条件下发生反式消除，同时水解邻二羟基缩酮保护，完 成了 $(+)$-lycoricidine 的合成. 另外, 环硫酸酯 94 在 $\mathrm{PhCOONa}$ 条件下同样在 $\mathrm{C}(1)$ 位发生开环反应, 酸性条 件下水解缩酮, 碱性条件下水解酯基后完成了 $(+)-7-$ deoxy-pancratistatin 的合成(Scheme 15).

孙兴文课题组发展了钯催化的醋酸肉桂醇酯与手 性叔丁基亚磺酰亚胺的不对称 1,2-加成反应，避免使用 不稳定的肉桂基卤化物, 扩展了制备光学纯的 $\beta$-芳基高
烯丙基胺的底物范围.

另外，该课题组应用类似的策略完成了天然产物 $(-)$ - $\alpha$-lycorane 和 $(-)$-zephyranthine 的全合成, 以及 $(+)$-clivonine 的形式合成 ${ }^{[29]}$.

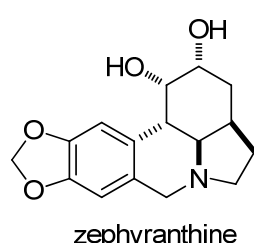<smiles>CN1CC[C@H]2C[C@@H](O)[C@H]3OC(=O)c4cc5c(cc4[C@H]3[C@@H]21)OCO5</smiles><smiles>COc1cc2c(cc1OC(C)(C)C)[C@H]1CCCC3CCN(C2)C31</smiles>

1.1.4 叔丁基亚磺酰亚胺与其他碳负离子的 1,2-加成 反应

2006 年, Chemla 课题组 ${ }^{[30]}$ 通过手性叔丁基亚磺酰 亚胺的 1,2-加成反应一步构建了 2 个立体中心，从而实 现了( - )-1-hydroxyquinolizidinone 的不对称合成 (Scheme 16).

5-氯戊醛 95 为起始物与 $(S)$-叔丁基亚磺酰胺缩合 可得到叔丁基亚磺酰亚胺 96, 其与联烯锌试剂 97 发生 不对称的 1,2-加成反应, 引入胺的 $\alpha$ 位和 $\beta$ 位 2 个立体 中心，得到炔烃化合物 98, $d r$ 值为 $24: 1$. 在 $\mathrm{NaH}$ 条件 下，化合物 98 发生分子内 $\mathrm{S}_{\mathrm{N}} 2$ 反应构建哌啶环，并脱除 TMS 保护基, 得到单一异构体 99. 接着化合物 99 经过 4 步转化实现了(一)-1-hydroxyquinolizidinone 的合成. 借 鉴黄培强课题组 ${ }^{[31]}$ 报道的策略可以完成 $(-)$-epiquinamide 和(一)-homopumiliotoxin $223 \mathrm{G}$ 的形式合成.<smiles>COC1O[C@@H](CI)C2OC(C)(C)OC12</smiles>

88

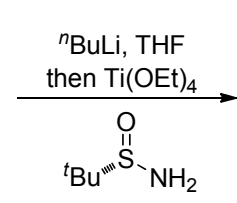<smiles>C=CC1OC(C)(C)OC1/C=N/S(=O)C(C)(C)C</smiles>

89

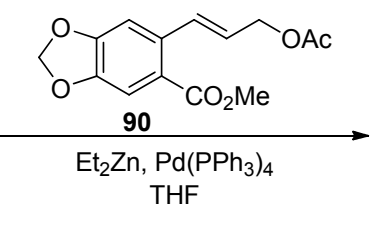

THF

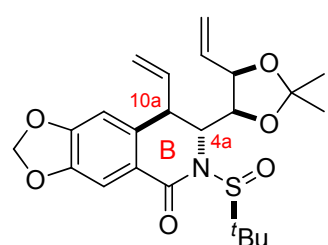

91
Grubbs $2^{\text {nd }}$ cat. toluene, $79 \%$

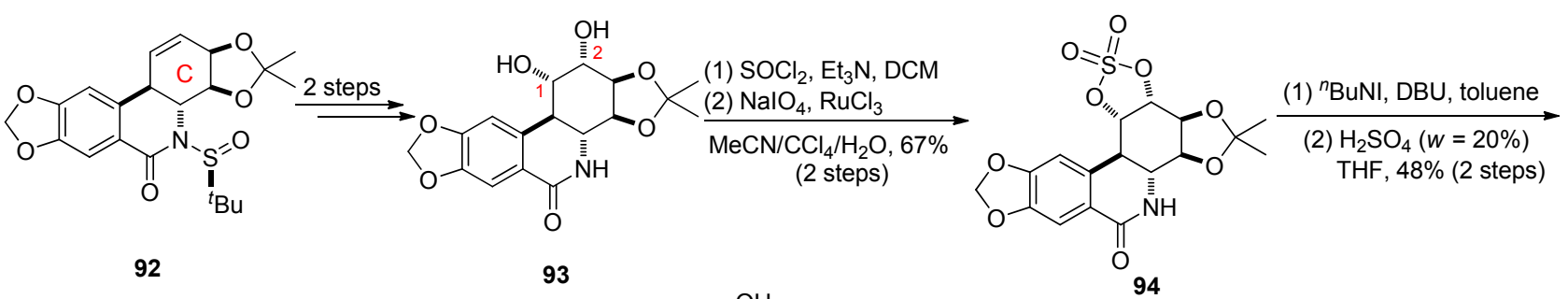<smiles>O=C1N[C@H]2C(=C[C@H](O)C(O)C2O)c2cc3c(cc21)OCO3</smiles>

(+)-lycoricidine<smiles>O=C1N[C@H]2C(O)C(O)[C@@H](O)C(O)[C@@H]2c2cc3c(cc21)OCO3</smiles>

(+)-7-deoxypancratistatin
(1) $\mathrm{PhCOONa}, \mathrm{DMF}$

(2) $\mathrm{H}_{2} \mathrm{SO}_{4}(w=20 \%), \mathrm{THF}$

(3) $\mathrm{NaOMe}, \mathrm{MeOH}, 97 \%$

图式 15 孙兴文课题组关于 $(+)$-lycoricidine 和 $(+)-7$-deoxypancratistatin 的全合成

Scheme 15 Total synthesis of $(+)$-lycoricidine and $(+)$-7-deoxypancratistatin by Sun group 

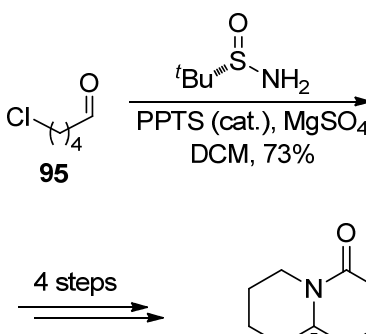<smiles>O=C1CC[C@@H](O)[C@H]2CCCCN12</smiles>

(-)-1-hydroxyquinolizidione<smiles>CC(C)C[As](=O)N=CC(=O)O</smiles>
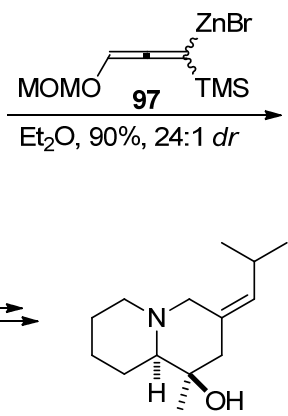

(-)-homopumiliotoxin 223G<smiles>CO[C@H](C=O)[C@@H](C#C[AlH2])NS(=O)CC(C)C</smiles>

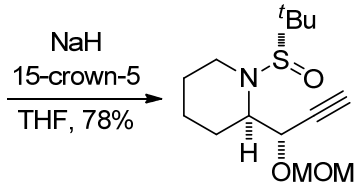

99 (single isomer)

图式 16 Chemla 课题组关于(-)-1-hydroxyquinolizidinone 的全合成

Scheme 16 Total synthesis of (-)-1-hydroxyquinolizidinone by Chemla group

Chemla 课题组从(S)-叔丁基亚磺酰胺出发, 经过 7 步转化, 以 $25.2 \%$ 的总产率高效合成(-)-1-hydroxyquinolizidinone. 利用叔丁基亚磺酰亚胺可以引入天然 产物所需的氮原子, 并高选择性地完成立体中心的构 建.

Chemla 课题组通过该策略还完成了(一)- $\alpha$-conhydrine、(+)-6-epi-castanospermine 和(-)-balanol 的合成 以及(+)-CP-99,994、(+)-CP-99,994 和(+)-CP-122,721 的形式合成 ${ }^{[32]}$.<smiles>CCC(O)C1CCCCN1</smiles>

$(-)-\alpha$-conhydrine<smiles>O=C(NC1CNCCCC1OC(=O)c1cc(O)c(C(=O)c2c(O)cccc2C(=O)O)c(O)c1)c1ccc(O)cc1</smiles>

(-)-balanol

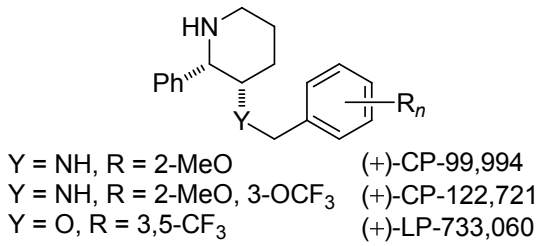

2010 年, 赵刚课题组 ${ }^{[33]}$ 报道了 $(-)$-fasicularin 和 (一)-lepadiformine A 的不对称全合成, 作者利用手性叔 丁基亚磺酰亚胺与烯丙基锌发生不对称 1,2-加成反应引 入 $\mathrm{C}(10)$ 位立体中心.

以易得的手性酮 100 为起始物，与 $(R)$-叔丁基亚磺 酰胺缩合得到 101. 烯丙基溴和锌原位生成的烯丙基锌 与亚胺 101 通过螯合作用, 经过椅式过渡态, 发生不对 称烯丙基化反应构建 $\mathrm{C}(10)$ 位氮杂季碳手性中心, 得到
化合物 102, $d r$ 值为 $12: 1$. 化合物 $\mathbf{1 0 2}$ 经过 3 步官能团 转化生成化合物 103, 经过 Ley 氧化生成醛后自发环化 得到化合物 104. 接着经过 4 步转化生成化合物 $105 \mathrm{a}$ 和 105b. 在 $\mathrm{NaH}$ 作用下，化合物 105a 发生 $\mathrm{S}_{\mathrm{N}} 2$ 反应构建 氮杂五元环化合物 106, 经过 5 步转化生成化合物 107. 在钠䒺条件下化合物 107 脱除 $\mathrm{Ts}$ 保护基，经过分子内环 化生成不稳定的烯胺 108, 通过 Luche 还原生成单一异 构体的化合物 109. 用四丁基氟化铵(TBAF)脱除硅基保 护基，最后在 Mitsunobu 反应条件下引入硫氰基，完成 了(一)-fasicularin 的合成. 另外, 用 $L$-selectride 还原化 合物 107, 可以得到预期构型的化合物 110, $d r$ 值为 6 ：

1. 化合物 110 在钠菜条件下脱除 Ts 保护基, 然后在 4二甲氨基吡啶 (DMAP) 催化作用下发生分子内类 Mitsunobu 环化反应构建氮杂六元环，最后脱除保护基 合成(一)-lepadiformine A (Scheme 17).

赵刚课题组使用手性辅基叔丁基亚磺酰胺，利用亚 磺酰基与锌配位，以较好的非对映选择性引入氮杂季碳 手性中心, 这对该家族的其他氮杂螺三环生物碱不对称 全合成有一定借鉴意义.

2011 年, Andrade 课题组 ${ }^{[34]}$ 报道了(-)-leuconicine A 和(一)-leuconicine B 的不对称全合成. 他们利用手性叔 丁基亚磺酰亚胺的烯丙基化反应构建 $\mathrm{C}(21)$ 位立体中心, 后续通过该立体中心诱导 $\mathrm{C}(7)$ 位立体中心的生成; 连续 一锅螺环化/分子内 $a z a$-Baylis-Hillman 反应构建 $\mathrm{ABCE}$ 骨架; 串联 acylation/Knoevenagel 反应构筑 $\mathrm{F}$ 环; 分子 内 Heck 环化反应构建 D 环，继而实现(一)-leuconicine A 和(一)-leuconicine B 的全合成.

起始物 111 和 $(R)$-叔丁基亚磺酰胺在 $\mathrm{Ti}(\mathrm{OEt})_{4}$ 作用 下缩合生成叔丁基亚磺酰亚胺，与原位产生的烯丙基铟 试剂反应 ${ }^{[35]}$, 以高收率和较好的立体选择性得到高烯 丙基胺 112, $d r$ 值为 $10: 1$. 化合物 112 经过脱除亚磺酰 基保护并修饰胺基以及引入边链等 5 步转化得到化合物 113. 在 $\mathrm{AgOTf}$ 和 2,6-二叔丁基-4-甲基吡啶(DTBMP)的 作用下，化合物 113 发生分子内螺环化反应引入 C(7)位 

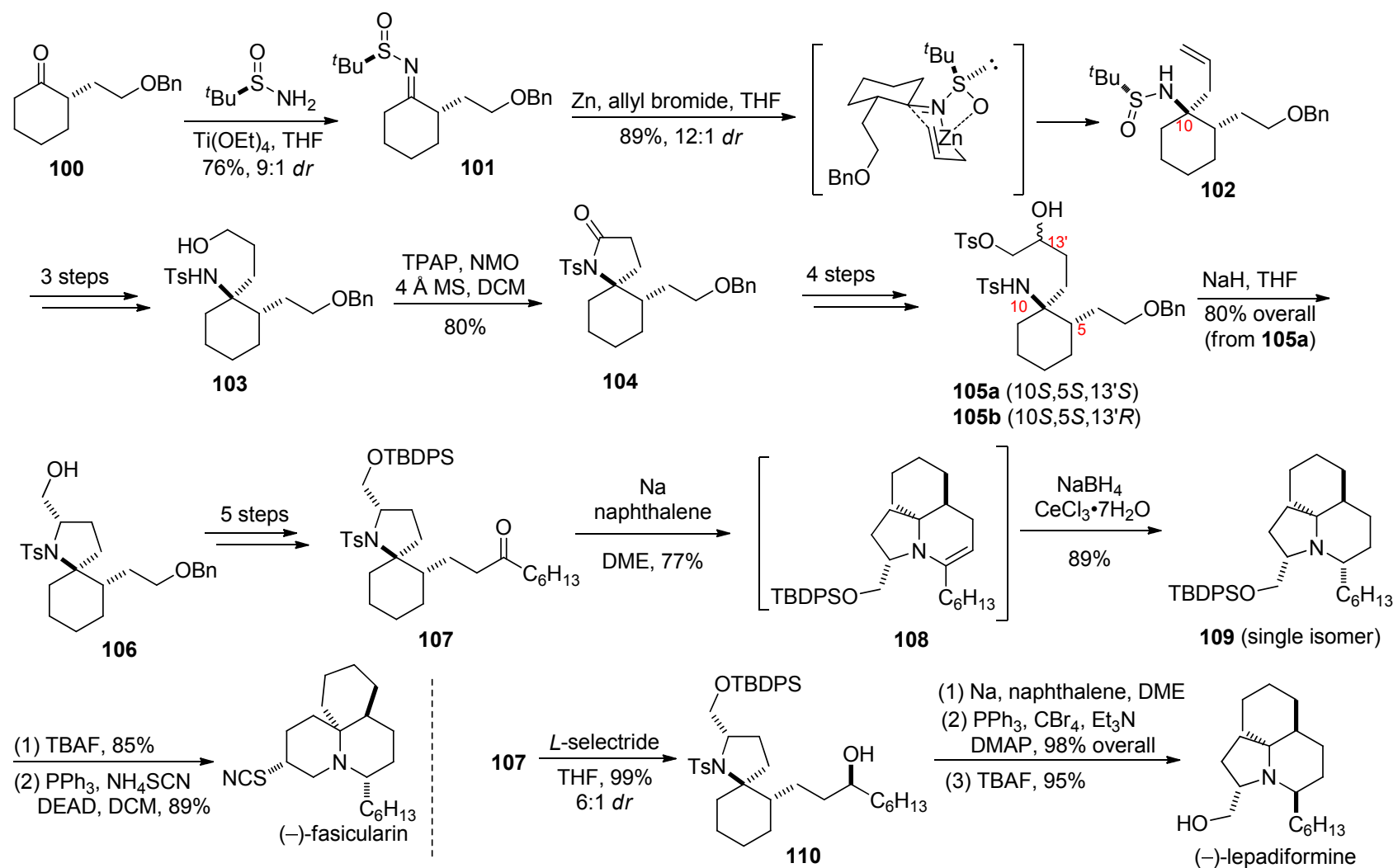

图式 17 赵刚课题组关于(-)-fasicularin 和(-)-lepadiformine A 的全合成

Scheme 17 Total synthesis of (-)-fasicularin and ( - -)-lepadiformine A by Zhao group

螺环手性中心, 随后在 DBU 作用下发生 $a z a$-BaylisHillman 反应构建 E环, 同时引入 C(2)位手性中心, 得到 具有 $\mathrm{ABCE}$ 四环结构的化合物 115. 化合物 115 经过 4 步转化调整分子的氧化态, 得到的化合物 116 与酰氯 117 在 $\mathrm{Et}_{3} \mathrm{~N}$ 作用下发生串联 acylation/Knoevenagel 反应 构建 F 环, 生成化合物 118 . 在钯催化下, 化合物 118 发 生分子内 Heck 反应构筑 D 环, Raney Ni 还原环外双键 可以得到(一)-leuconicine B. (一)-leuconicine B 经过氨解 可以转化为(一)-leuconicine A (Scheme 18).

作者使用连续一锅螺环化/分子内 $a z a$-Baylis-Hillman 反应构建 ABCE 骨架, 串联 acylation/Knoevenagel 反应构筑 $\mathrm{F}$ 环, 分子内 Heck 环化反应构建 $\mathrm{D}$ 环, 高效 地构建了 (一)-leuconicine A 和(一)-leuconicine B 的骨架.

2011 年, González-Gómez 课题组 ${ }^{[36]}$ 报道了(一)aphanorphine 的全合成. 他们利用手性叔丁基亚磺酰亚 胺的烯丙基化反应实现仲胺立体中心的构建, 继而通过 后续的转化合成(一)-aphanorphine.

起始物 4-甲氧基苯乙醛(120)与 $(R)$-叔丁基亚磺酰胺 在 $\mathrm{Ti}(\mathrm{OEt})_{4}$ 作用下缩合生成叔丁基亚磺酰亚胺, 再与原 位产生的烯丙基铟试剂反应, 以高收率和立体选择性得 到高烯丙基胺 121, $d r$ 值为 $93: 7$. 化合物 121 与 $m$-CPBA 作用同时发生双键的环氧化和亚砜的氧化得到
砜基化合物 122, 在 $\mathrm{KI}$ 和 $\mathrm{K}_{2} \mathrm{CO}_{3}$ 条件下发生氮原子进攻 环氧开环构筑氮杂五元环, 得到化合物 123. 在 $\mathrm{AlCl}_{3}$ 作 用下 123 发生 Friedel-Crafts 烷基化得到三环化合物 125, 最后经过 3 步反应实现氮和氧原子上官能团的修饰得到 (一)-aphanorphine (Scheme 19).

该课题组合成 $(-)$-aphanorphine 使用的策略为不对 称合成桥环化合物提供了新思路.

此外, González-Gómez 课题组 ${ }^{[37]}$ 利用类似的策略还 合成了 tetraponerines T3, T4 和(一)-tylophorine.

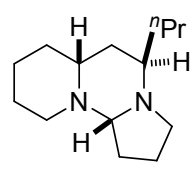

tetraponerines T3

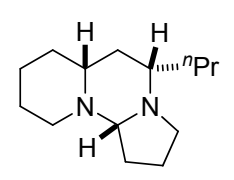

tetraponerines T4<smiles>COc1cc2c3c(c4cc(OC)c(OC)cc4c2cc1OC)C1CCCN(C3)C1</smiles>

(-)-tylophorine
2013 年, Evans 课题组 ${ }^{[38]}$ 报道了(一)-nakadomarin A 的全合成. (一)-Nakadomarin A 可以由内酰胺 134 和双环 [6.3.0] 内酰胺 130 两个片段连接、转化得到. 片段 130 中的手性中心控制了后续所有手性中心的产生，片段 130 中的手性中心则是通过叔丁基亚磺酰亚胺发生锌促 进的烯丙基化反应构建. 

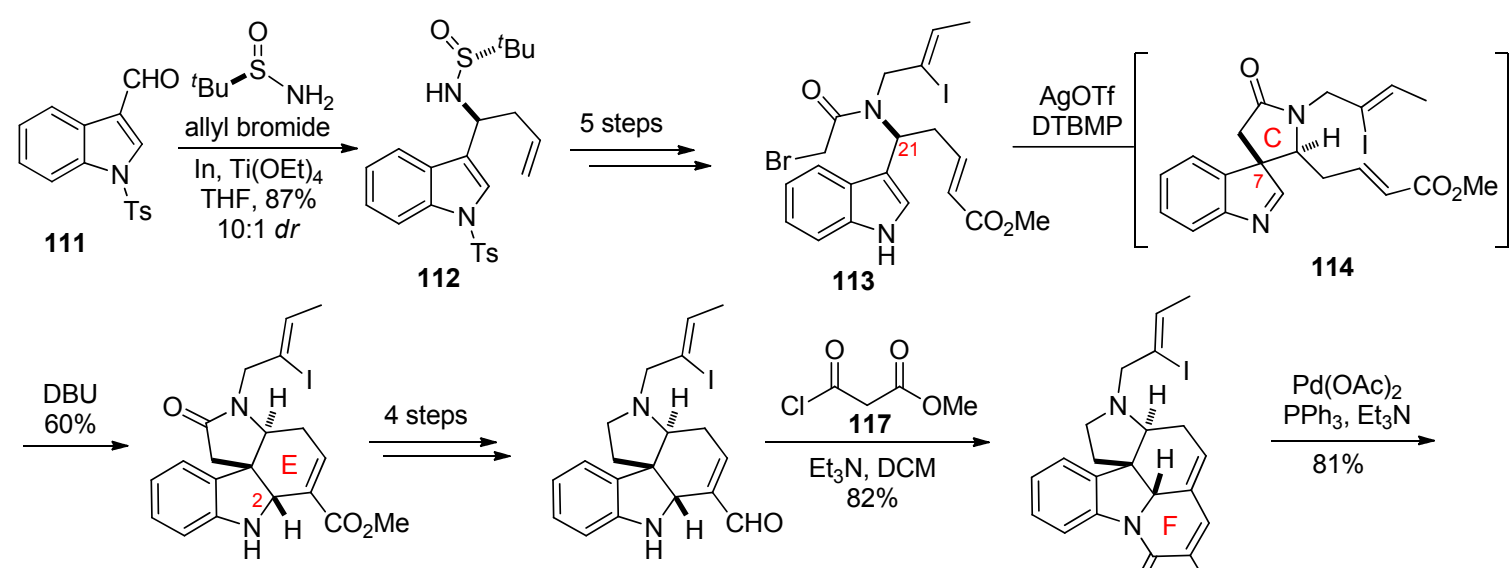

115

116
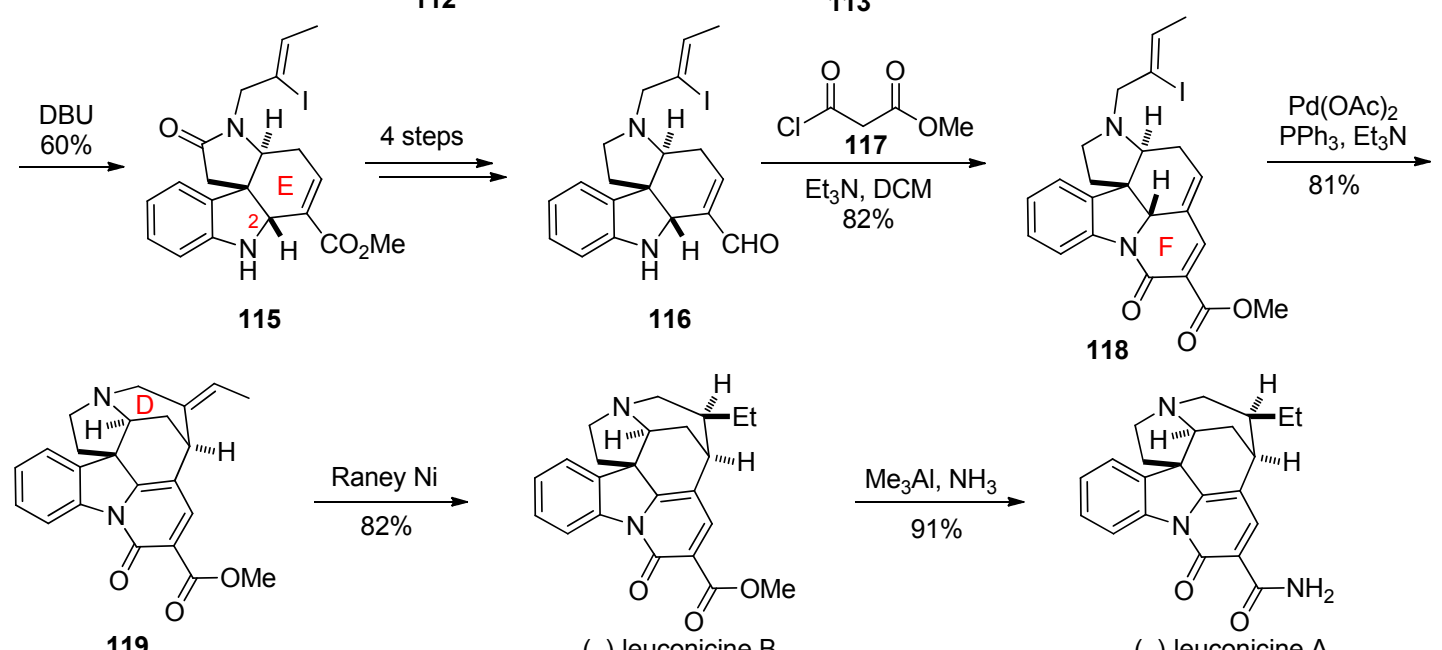

(-)-leuconicine B

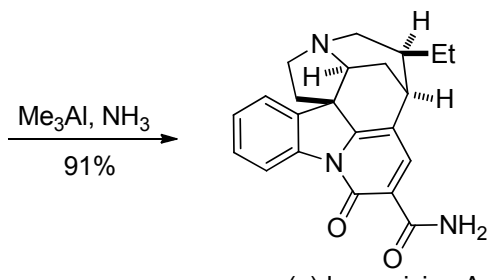

(-)-leuconicine A

图式 18 Andrade 课题组关于(-)-leuconicine A 和(一)-leuconicine B 的全合成 Scheme 18 Total synthesis of ( - )-leuconicine A and ( - -)-leuconicine B by Andrade group

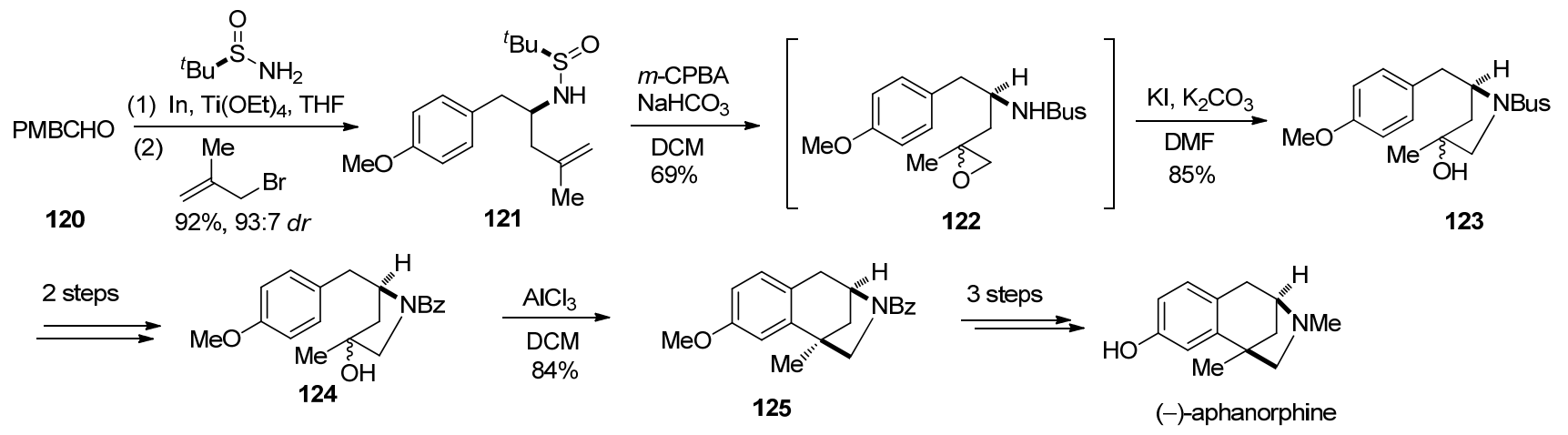

图式 19 González-Gómez 课题组关于 $(-)$-aphanorphine 的全合成

Scheme 19 Total synthesis of ( - -aphanorphine by González-Gómez and co-workers

作者首先合成双环 [6.3.0]内酰胺 130. 丙烯醛 126 和 $(R)$-叔丁基亚磺酰胺在 $\mathrm{Ti}(\mathrm{OEt})_{4}$ 作用下缩合生成叔丁基 亚磺酰亚胺 127. 亚胺 127 与原位生成的有机锌试剂发 生 $a z a$-Barbier 类型的反应 ${ }^{[39]}$ 生成化合物 129, 酸解脱除 叔丁基亚磺酰基, 在 $\mathrm{NaOH}$ 条件下发生内酰胺化后, 再 与 1-碘-5-己烯发生氮烷基化, 最后在第二代 Grubbs 催 化剂的催化下发生烯烃的关环复分解(RCM)反应构建 八元环, 生成双环[6.3.0]内酰胺 $\mathbf{1 3 0}$.

另外, 3-糠醛 131 经过 2 步转化得到化合物 132, 与 再烯丙醇发生分子间 Heck 偶联反应生成醛基化合物, 经过 Wittig 反应延长碳链, 生成以 $Z$-烯烃为主的产物, 然后经过脱保护、Still-Gennari 改进的 Horner-Wadsworth-
Emmons 反应 ${ }^{[40]}$, 生成 $Z$ 式 $\alpha, \beta$-不饱和酯 133. 化合物 133 经过 3 步转化生成内酰胺 134. 内酰胺 134 和双环 [6.3.0] 内酰胺 130 在叔丁基二甲硅基三氟甲磺酸酯 (TBSOTf)促进下发生双 Michael 加成反应，生成化合物 135 和预期构型 136, 构建了 (-)-nakadomarin A 的骨架. 化合物 136 在 $\mathrm{Tf}_{2} \mathrm{O}$ 和 2,6-二叔丁基-4-甲基吡啶条件下 活化酰胺, 与呋喃环发生分子内成环, 随后在 Red-Al 作 为还原剂的条件下得到(一)-nakadomarin A (Scheme 20).

Evans 课题组报道的合成策略巧妙地利用叔丁基亚 磺酰亚胺作为起始物, 通过加成反应引入手性中心, 继 而控制后续手性中心的产生，最终完成了(一)-nakadomarin $\mathrm{A}$ 的合成. 该策略体现了叔丁基亚磺酰亚胺在全 


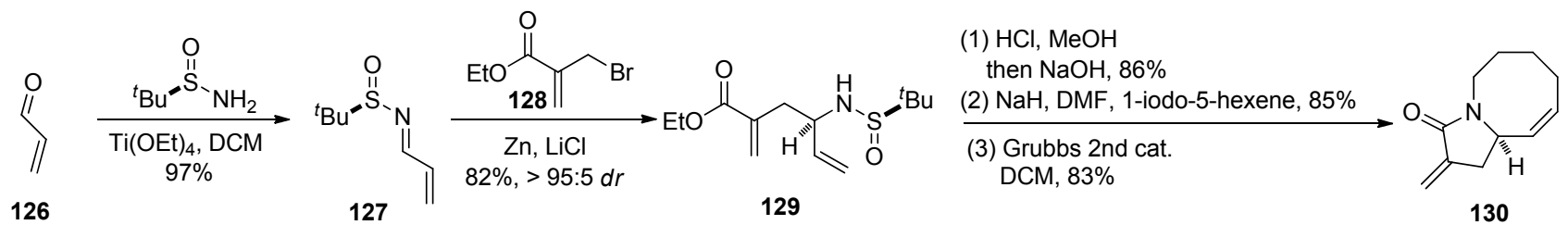

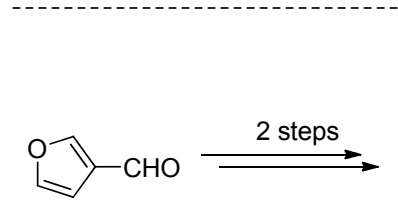

131

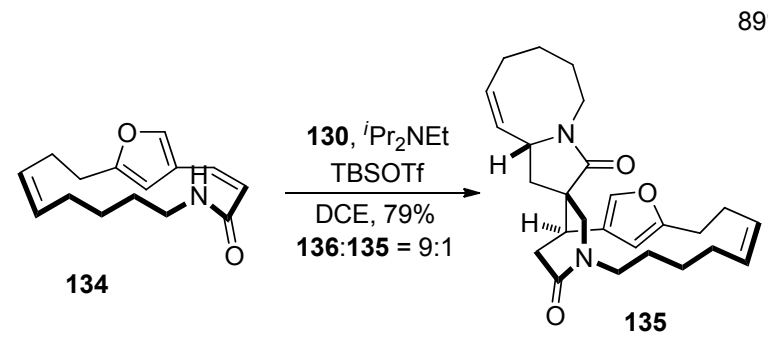

(1) $\mathrm{Pd}(\mathrm{OAc})_{2}$, allyl alcohol $\mathrm{NaHCO}_{3}$, DMF

(2) KHMDS, BocNH $\left(\mathrm{CH}_{2}\right)_{5} \mathrm{PPh}_{3} \mathrm{I}$ then $\mathrm{HCl}, 89 \%(Z: E>20: 1)$

(3) KHMDS, 18-crown-6 $\mathrm{CH}_{3} \mathrm{O}_{2} \mathrm{CCH}_{2} \mathrm{P}(\mathrm{O})\left(\mathrm{OCH}_{2} \mathrm{CF}_{3}\right)_{2}$ $89 \%(Z: E>20: 1)$

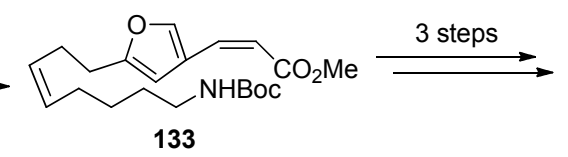

133
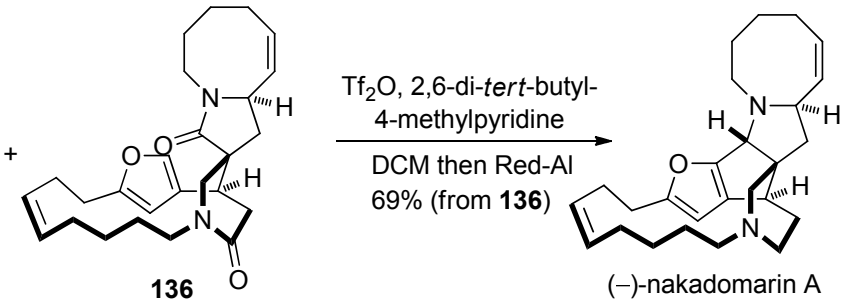

$(-)$-nakadomarin $\mathrm{A}$

图式 20 Evans 课题组关于 (-)-nakadomarin A 的全合成

Scheme 20 Total synthesis of (-)-nakadomarin A by Evans group

合成中引入重要手性中心的高效性.

2013 年, Andrade 课题组 ${ }^{[41]}$ 报道了(-)-melotenine A 的首次不对称全合成. 合成中通过手性叔丁基亚磺酰亚 胺的烯丙基化反应构建 $\mathrm{C}(21)$ 位立体中心，且该立体中 心诱导 $\mathrm{C}(7)$ 位立体中心的生成, 通过后续的转化实现了 $(-)$-melotenine A 的全合成.

起始物 111 和 $(R)$-叔丁基亚磺酰胺在 $\mathrm{Ti}(\mathrm{OEt})_{4}$ 作用 下缩合生成叔丁基亚磺酰亚胺，再与原位产生的烯丙基 铟试剂反应引入 $\mathrm{C}(21)$ 位立体中心, 并以高收率和较好 的立体选择性得到高烯丙基胺 112, $d r$ 值为 $10 ： 1$. 化合 物 112 经过 4 步转化引入边链以及脱除亚磺酰基保护得 到化合物 137. 在 Mitsunobu 反应条件下, 化合物 137 发 生螺环化实现 C(7)位螺环手性中心的构建, 在 DBU 加
热的条件下构建 $\mathrm{E}$ 环, 引入 $\mathrm{C}(2)$ 位手性中心, 生成具有 $\mathrm{ABCE}$ 四环结构的化合物 138. 该反应可能是经历了 $a z a$-Baylis-Hillman 或 是 vinylogous Mannich/olefin isomerization 的过程. 在 LDA 条件下, 化合物 $\mathbf{1 3 8}$ 结构 中的 $\alpha, \beta$-不饱和酯的 $\gamma$ 位去质子化形成碳负离子, 之后 与乙醛发生 aldol 反应, 催化氢化双键, 2,3-二氯-5,6-二 氧-1,4-苯醌(DDQ)氧化生成烯胺 139. 化合物 139 经过 3 步转化后得到化合物 $\mathbf{1 4 0}$, 最后在 ${ }^{n} \mathrm{BuLi}$ 条件下发生分 子内 Piers 环化构建 $\mathrm{D}$ 环, 在 $\mathrm{PPh}_{3}$ 和 $\mathrm{I}_{2}$ 的条件下 ${ }^{[14]}$ 实现 区域选择性脱水, 完成了(一)-melotenine A 的合成 (Scheme 21).

作者开发了新的环化顺序构建(一)-melotenine $\mathrm{A}$ 的 ABCE 四环骨架, 之后 Piers 螺环化反应构建 D 环最终<smiles>O=Cc1cn([Tl])c2ccccc12</smiles>

111

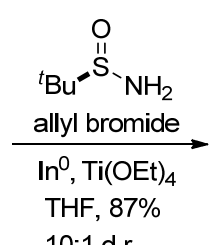

10:1 d.r.<smiles>C=CC[C@H](N[S@](=O)C[13CH3])c1cn(C)c2ccccc12</smiles>

112 Ts

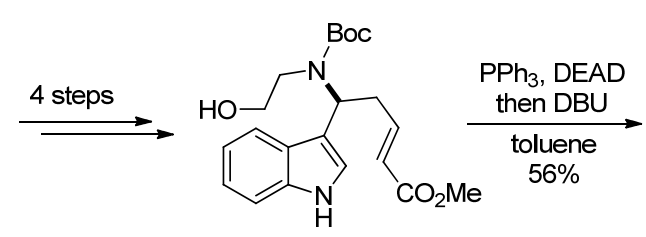

137

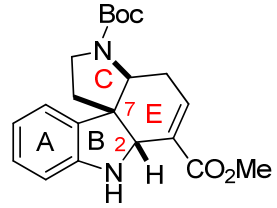

138

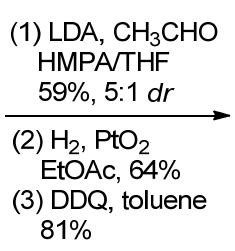

$81 \%$
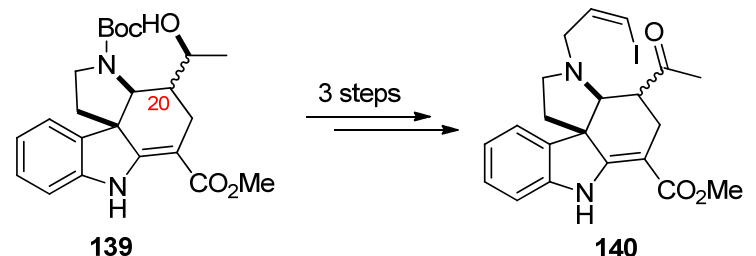

(1) ${ }^{n} \mathrm{BuLi}$ THF, $76 \%$ (2) $\mathrm{PPh}_{3}, \mathrm{I}_{2}$ $44 \%$

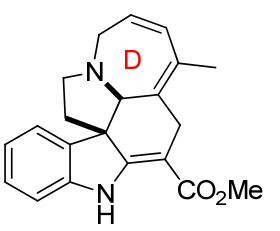

(-)-melotemine A

图式 21 Andrade 课题组关于(-)-melotenine A 的全合成

Scheme 21 Total synthesis of ( - -)-melotenine A by Andrade and co-workers 
构建天然产物的环系骨架. 其中叔丁基亚磺酰亚胺作为 手性源, 参与了关键手性中心的构建, 该策略为不对称 合成氮杂并环骨架提供了很好的借鉴.

2014 年, Davies 课题组 ${ }^{[42]}$ 报道了(-)-nakinadine A 的 全合成. 他们以苯乙酸甲酯和手性叔丁基亚磺酰亚胺发 生的 Mannich-type 反应作为关键步骤, 引入 C(2)和 C(3) 位的两个立体中心, 首次实现了不对称合成(一)-nakinadine A，并确定了其绝对构型.

以 11-溴-1-十一醇 141 为起始原料, 经过 5 步转化 延长碳链并引入吡啶基团得到化合物 142, 再与 $(R)$-叔 丁基亚磺酰胺缩合得到叔丁基亚磺酰亚胺 143. 甲基溴 化镁作为碱与苯乙酸甲酯作用生成烯醇负离子, 然后与 亚胺 143 发生立体选择性的 1,2-加成反应得到化合物 144 和预期构型产物 145, 二者比例为 $20 ： 80$. 酸性条 件下, 145 脱除叔丁基亚磺酰基，再与醛基化合物 146 发 生还原胺化反应生成化合物 147 , 最后经过酯基的水解 以及纯化完成了天然产物(一)- $(2 S, 3 R, Z)$-nakinadine A 的 合成. 该课题组 ${ }^{[43]}$ 应用该方法还合成了 nakinadines $D$, E, F (Scheme 22).

Davies 课题组采用叔丁基亚磺酰亚胺的不对称 Mannich-type 反应为关键步骤, 经过 11 步线性转化, 以 9\%的收率得到了天然产物(一)-nakinadine A.

2015 年, 黄培强课题组 ${ }^{[44]}$ 以叔丁基亚磺酰亚胺的 不对称 vinylogous Mannich 反应为关键步骤，完成了 pandamarilactonines $\mathrm{A} \sim \mathrm{C}$ 的全合成.

他们以 $(R)$-叔丁基亚磺酰胺与 4-氯丁醛(148)为原 料, 在 $\mathrm{CuSO}_{4}$ 促进下缩合生成叔丁基亚磺酰亚胺 149.
呋喃 150 与 149 发生不对称 vinylogous Mannich 反应, 得到以化合物 $s y n-151$ 为主的产物, $d r$ 值为 $95: 5$. 化合 物 syn-151 在盐酸作用下脱去叔丁基亚磺酰基，再在 $\mathrm{K}_{2} \mathrm{CO}_{3}$ 作用下发生分子内 $\mathrm{S}_{\mathrm{N}} 2$ 反应，可以构建吡咯环生 成化合物 152. 在这个过程中 $\mathrm{C}(15)$ 位手性中心发生了 一定程度的消旋化. 化合物 152 和片段 153 经过氮烷基 化反应得到 pandamarilactonines $\mathrm{A} \sim \mathrm{C}$ (Scheme 23). 黄 培强课题组利用叔丁基亚磺酰亚胺与呋喃发生 vinylogous Mannich 反应，引入相邻的 2 个手性中心，高效构 建了 5-吡咯烷基-呋喃-2-酮片段, 继而合成 pandamarilactonines $\mathrm{A} \sim \mathrm{C}$.

黄培强课题组使用叔丁基亚磺酰亚胺的不对称 vinylogous Mannich 反应还完成了 $(+)$-absouline 和 $(-)$ deoxoprosophylline 的全合成以及 $L$-deoxyallonojirimycin 和 $L$-3-epi-fagomine 的形式合成 ${ }^{[45]}$.

2016 年, 孙兴文课题组 ${ }^{[46]}$ 利用 $a z a$-Barbier 烯丙基 化反应一步引入两个相邻的立体中心, 以生成的产物作 为通用中间体完成了 amathaspiramides B, D, F 的不对称 全合成。

酮 154 和 $(S)$-叔丁基亚磺酰胺缩合生成叔丁基亚磺 酰亚胺 155, 再与原位产生的烯丙基溴化锌发生烯丙基 化反应引入 $\mathrm{C}(5)$ 位和 $\mathrm{C}(9)$ 位 2 个相邻的立体中心, 生成 $157 \mathbf{a}$ 和 $157 \mathrm{~b}, d r$ 值为 $10: 1$. 从期望构型化合物 157a 出发, 在盐酸作用下脱除亚磺酰基, 在 $\mathrm{Et}_{3} \mathrm{~N}$ 条件下发生 内酰胺化得到化合物 158, 随后经过 2 步官能团转化生 成 159. 之后化合物 159 发生甲基化, 氧化切断端烯生 成醛，与胺基发生环化合成 amathaspiramide B. 另外化
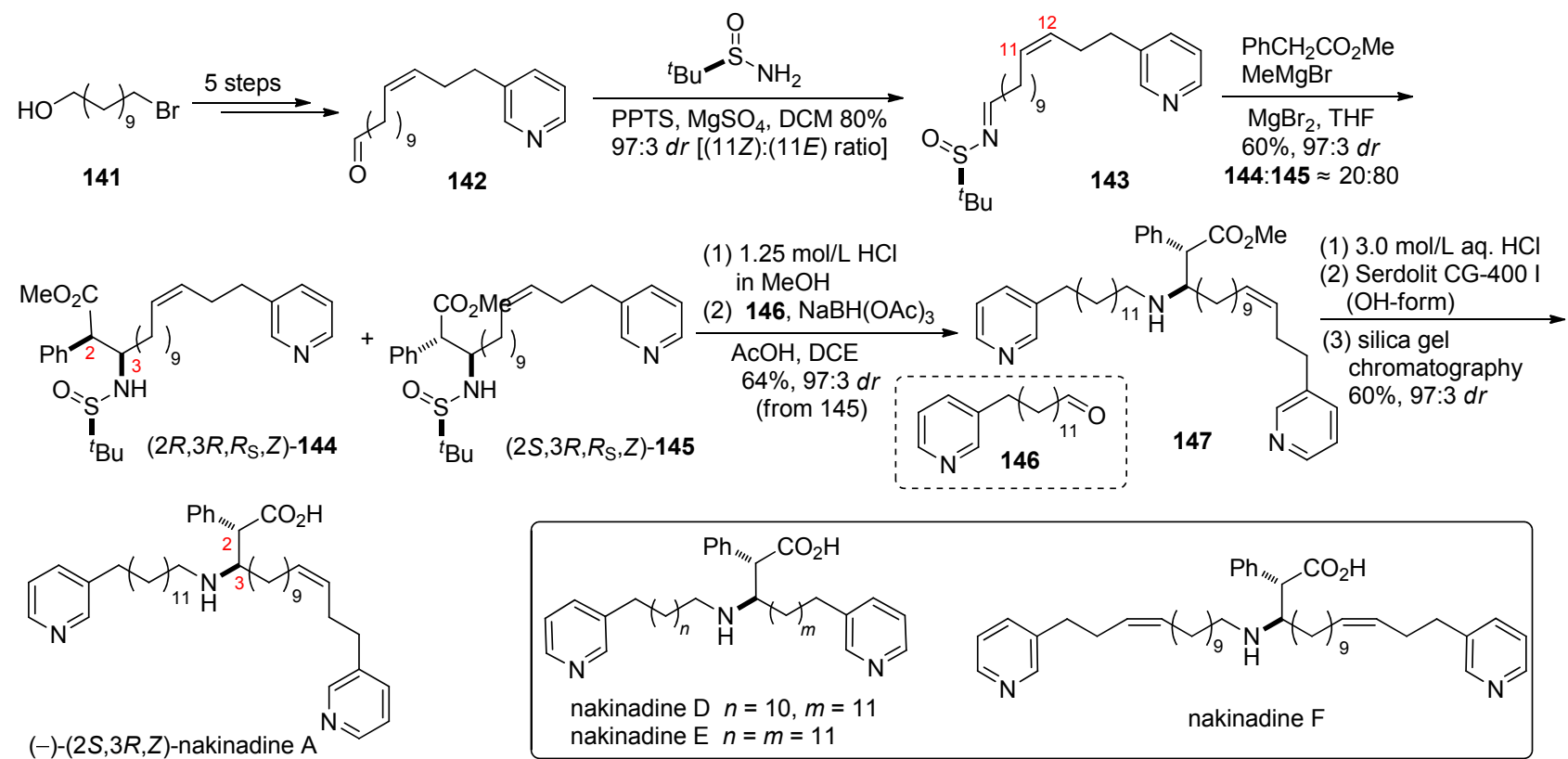

图式 22 Davies 课题组关于(-)-nakinadine A 的全合成

Scheme 22 Total synthesis of ( - )-nakinadine A by Davies group 


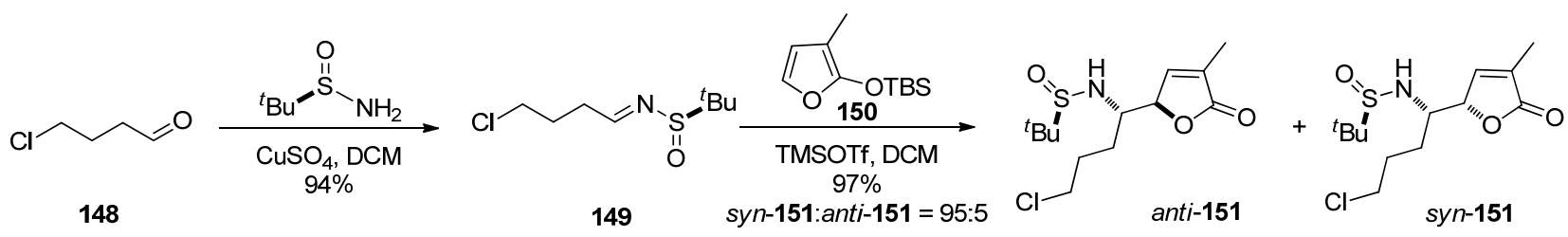

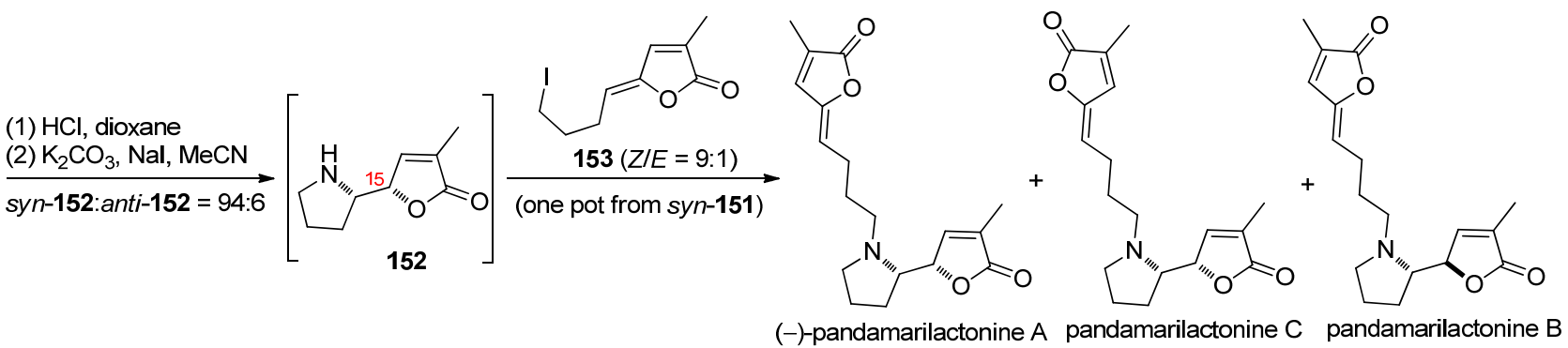
$(95.5 \%$ ee $)$

图式 23 黄培强课题组关于 pandamarilactonines $\mathrm{A} \sim \mathrm{C}$ 的全合成

Scheme 23 Total synthesis of pandamarilactonines $A \sim C$ by Huang group<smiles>COc1ccc(/C=C/C(=O)NC2CCN3CCCC23)cc1</smiles><smiles>[X]C1CNC(CC)C(O)[C@H]1O</smiles>

$\mathrm{OH}$

$L$-deoxyallonojirimycin $(X=\mathrm{OH})$

$L$-3-epi-fagomine $(\mathrm{X}=\mathrm{H})$

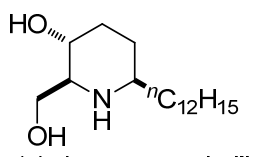

(-)-deoxoprosophylline

合物 159 直接经过臭氧切断、胺基缩合生成 amathaspiramide $\mathrm{D}$ 和 160. 选择性还原酰胺 160 可以得到天然产物 amathaspiramide F (Scheme 24).

作者通过芳基烯丙基溴化物与叔丁基亚磺酰亚胺 发生 $a z a$-Barbier 烯丙基化反应高效地合成具有两个相 邻立体中心的中间体，之后经过 4 步克级转化并以 $63 \%$ 的收率合成 amathaspiramide $\mathrm{D}$; 另外分别经过 5 步、 4 步转化可以分别合成 amathaspiramide B 和 amathaspiramide F.

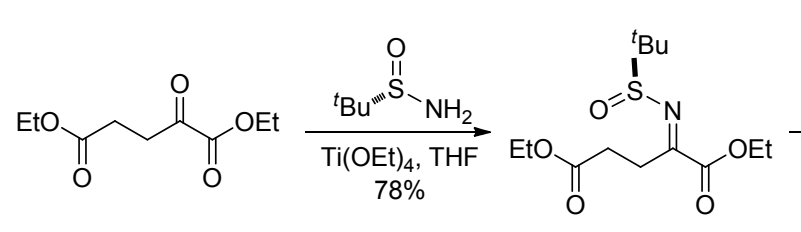

154
155<smiles>C=CC(c1cc(OC)c(Br)cc1Br)[C@]1(C(=O)N[14CH3])CCC(=O)N1</smiles>

(1) $\mathrm{NaH}, \mathrm{Mel}$ (2) $\mathrm{O}_{3}, \mathrm{DCM}$ then $\mathrm{PPh}_{3}$ $46 \%$<smiles>C=CC(c1cc(OC)c(Br)cc1Br)[C@@](CCC(=O)OCC)(NS(=O)CC(C)C)C(=O)OCC</smiles>

$157 a$<smiles>C=CC(c1cc(OC)c(Br)cc1Br)[C@@](CCC(=O)OCC)(NS(=O)CC(C)(C)C)C(=O)OCC</smiles>

157b
158<smiles>COc1cc(C2[C@H](O)N(C)C(=O)[C@]23CCCN3)c(Br)cc1Br</smiles>

amathaspiramide $\mathrm{F}$
$\mathrm{Cp}_{2} \mathrm{Zr}(\mathrm{H}) \mathrm{Cl}$, THF then $\mathrm{NaH}_{3} \mathrm{BCN}$ $51 \%$<smiles>COc1cc(C2[C@H](O)N(C)C(=O)[C@]23CCC(=O)N3)c(Br)cc1Br</smiles>

160 (33\%)
$\mathrm{O}_{3}, \mathrm{DCM}$ then $\mathrm{PPh}_{3}$<smiles>COc1cc(C2C(O)N(C)C(=O)[C@]23CCC(=O)N3)c(Br)cc1Br</smiles>

amathaspiramide D (65\%)<smiles>COc1cc(C2[C@H](O)N(C)C(=O)[C@]23CCC(=O)N3C)c(Br)cc1Br</smiles>

amathaspiramide B

图式 24 孙兴文课题组关于 amathaspiramides B, D, F 的全合成

Scheme 24 Total synthesis of amathaspiramides B, D, F by Sun and co-workers 
2017 年, 贾彦兴课题组 ${ }^{[47]}$ 报道了 8 个 $\operatorname{ergot}$ 生物碱 的全合成. 他们利用手性叔丁基亚磺酰亚胺的炔丙基化 反应引入 $\mathrm{C}(5)$ 位立体中心; 使用钯催化的 Larock 吲哚 环化反应 ${ }^{[48]}$ 或串联钯催化的分子内 Larock 吲哚环化/ Tsuji-Trost 烯丙基化反应，可以高效完成环系骨架的构 建.

他们从溴化物 161 出发, 经过 5 步转化得到叔丁基 亚磺酰亚胺 162, 与原位生成的联烯锌试剂 ${ }^{[49]}$ 发生炔丙 基化反应引入 $\mathrm{C}(5)$ 位立体中心, 生成 $163 \mathrm{a}$ 和 $163 \mathrm{~b}$. 化 合物 163a 和 163b 可以分别转化成不同的 ergot 生物碱. 首先在 $\mathrm{Pd}(\mathrm{OAc})_{2}$ 和 $\mathrm{Me}-\mathrm{Phos}$ 的催化体系中, 化合物 $163 \mathrm{a}$ 发生串联分子内 Larock 吲哚环化/Tsuji-Trost 烯丙 基化反应一步构建 $\mathrm{BCD}$ 三个环, 生成具有四环核心骨 架的化合物 164, 再经过 3 步转化对氮原子和吲哚 2 位 取代基进行修饰, 得到化合物 165, 再在 Raney $\mathrm{Ni}$ 和 $\mathrm{H}_{2}$ 条件下还原双键, 以 $5: 3$ 的比例得到天然产物 festuclavine 和 pyroclavine. Festuclavine 在 $N$-溴代丁二酰亚胺 (NBS)作用下发生 $\mathrm{C}(2)$ 位溴代生成 pibocin A. Festu- clavine 在 $t$ - $\mathrm{BuOCl}$ 条件下进行氯代后, 再与异戊二烯 基-9-BBN ${ }^{[50]}$ 反应生成 9-deacetoxyfumigaclavine $\mathrm{C}$. 另外 pyroclavine 经过相同的过程完成了 fumigaclavine $\mathrm{G}$ 的合 成. 化合物 $163 b$ 在 $\mathrm{Pd}(\mathrm{OAc})_{2}$ 和 $\mathrm{Me}-\mathrm{Phos}$ 的催化体系中 只能发生分子内 Larock 吲哚环化反应构建 $\mathrm{B}$ 和 $\mathrm{C}$ 两个 环，生成三环化合物 166. 化合物 166 经过 4 步转化关 D 环并完成对取代基的修饰得到 167, 在 Crabtree 催化剂 及 $\mathrm{H}_{2}$ 条件下还原双键, 最终以 $1: 1.2$ 的比例得到 costaclavine 和 epi-costaclavine (Scheme 25).

另外，四环化合物 164 发生 Mukaiyama 反应 ${ }^{[51]}$ 生成 醇 $168 \mathrm{a}$ 和 $168 \mathrm{~b}$, 其中 $168 \mathrm{a}$ 经过 3 步转化完成官能团修 饰得到天然产物 dihydrosetoclavine, 而 $168 \mathrm{~b}$ 经过类似的 3 步转化得到 iso-dihydrosetoclavine (Scheme 26).

作者通过叔丁基亚磺酰胺诱导的不对称炔丙基化 反应构建了关键的 $\mathrm{C}(5)$ 氮杂手性中心，并通过串联钯催 化的分子内 Larock 吲哚环化/Tsuji-Trost 烯丙基化反应 一步高效地构建了 ergot 生物碱的环系骨架，从而多样 性地合成了 ergot 生物碱.

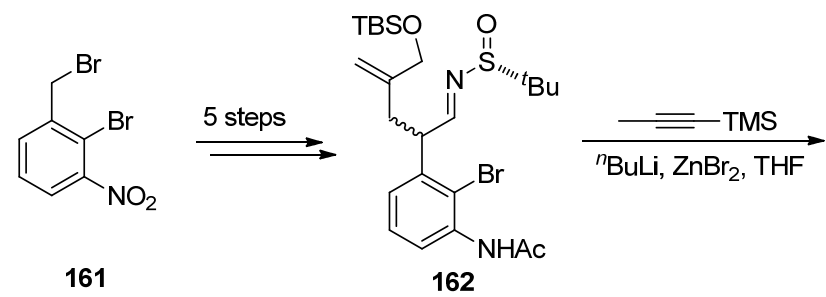

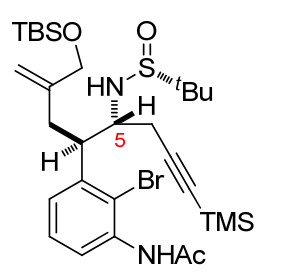

$163 a(43 \%)$

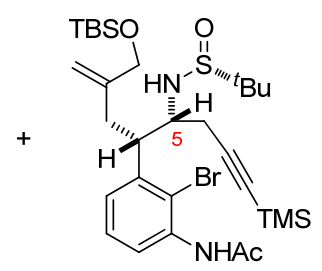

163b $(44 \%, 1: 3.4 d r)$

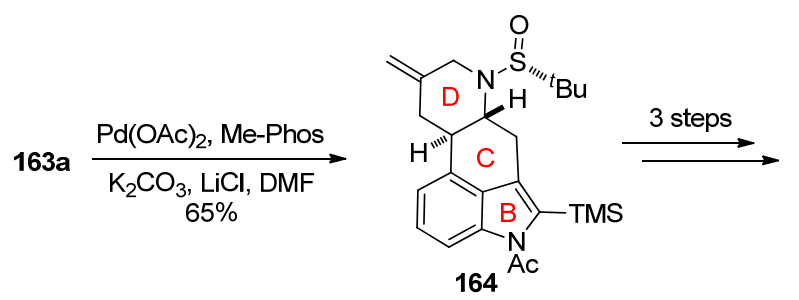

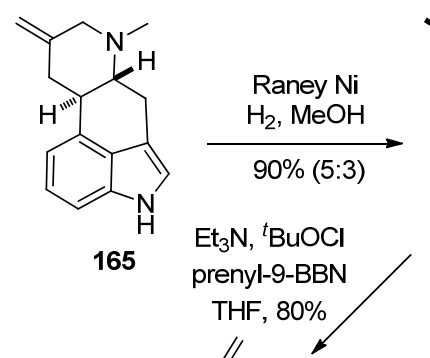<smiles>C=CC(C)(C)c1[nH]c2cccc3c2c1CC1(C)[C@@H]3CC(C)CN1C</smiles>

9-deacetoxyfumigaclavine $\mathrm{C}$

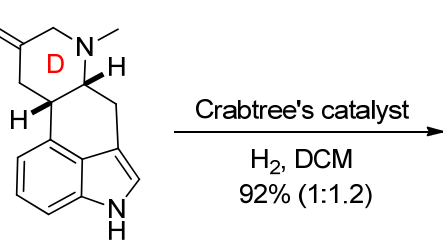

167

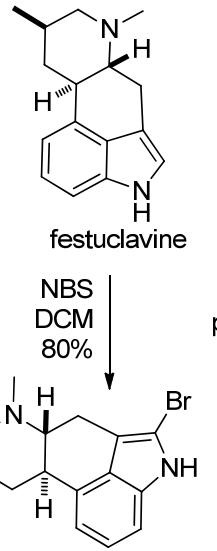

pibocin A

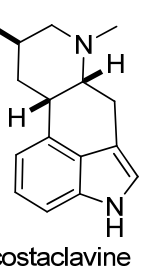

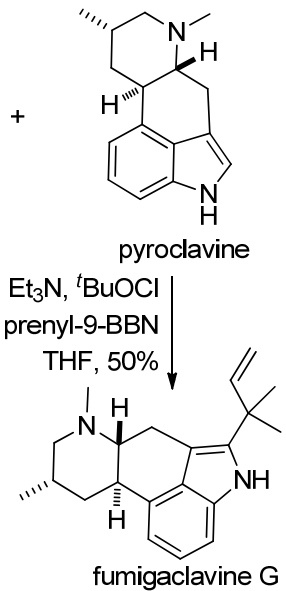

fumigaclavine $\mathrm{G}$

$\mathrm{K}_{2} \mathrm{CO}_{3}, \mathrm{LiCl}$
$\mathrm{DMF}, 55 \%$

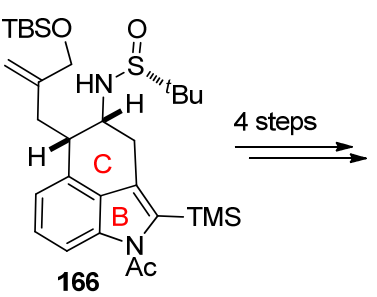

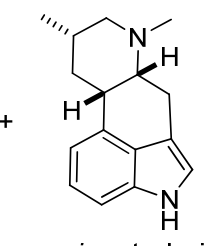

epi-costaclavine

图式 25 贾彦兴课题组关于 festuclavine, pyroclavine, costaclavine, epi-costaclavine, pibocin A, 9-deacetoxyfumigaclavine C 和 fumigaclavine $\mathrm{G}$ 的全合成

Scheme 25 Total synthesis of festuclavine, pyroclavine, costaclavine, epi-costaclavine, pibocin A, 9-deacetoxyfumigaclavine C and fumigaclavine $\mathrm{G}$ by Jia group 
<smiles>C=C1C[C@@H]2c3cccc4c3c(c(C)n4C)C[C@H]2N(S(=O)Cc2ccccc2)C1</smiles>

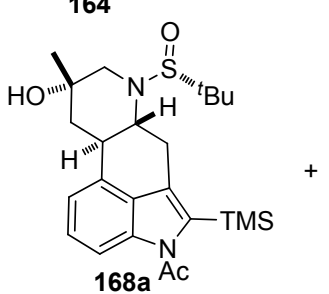

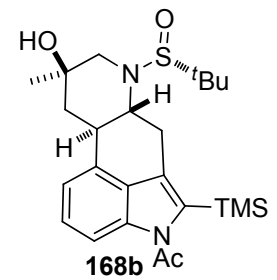<smiles></smiles><smiles>CN1C[C@](C)(O)C[C@H]2c3cccc4[nH]cc(c34)C[C@H]21</smiles>

dihydrosetoclavine

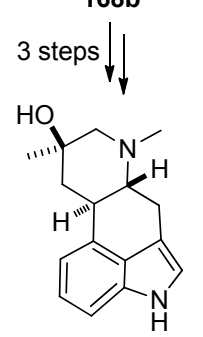

iso-dihydrosetoclavine

图式 26 贾彦兴课题组关于 dihydrosetoclavine 的全合成 Scheme 26 Total synthesis of dihydrosetoclavine by Jia group

除此之外, 应用叔丁基亚磺酰亚胺与碳负离子的<smiles>CC(CC(=O)N[C@@H](C[C@H](C)C(Cl)(Cl)Cl)C(=O)N(C)[C@@H](C)c1nccs1)C(Cl)(Cl)Cl</smiles><smiles></smiles><smiles>[X]C([X])([X])C(C)C[C@H]1[C@@H](OC)C=C(C)N1C(=O)[C@H](C[C@@H](C)C(Cl)(Cl)Cl)NC(=O)CC</smiles>

sintokamide $\mathrm{A}, \mathrm{X}=\mathrm{H}, \mathrm{Cl}, \mathrm{Cl}$ sintokamide $\mathrm{B}, \mathrm{X}=\mathrm{Cl}, \mathrm{Cl}, \mathrm{Cl}$ sintokamide $\mathrm{D}, \mathrm{X}=\mathrm{H}, \mathrm{H}, \mathrm{Cl}$ sintokamide $\mathrm{E}, \mathrm{X}=\mathrm{H}, \mathrm{H}, \mathrm{H}$

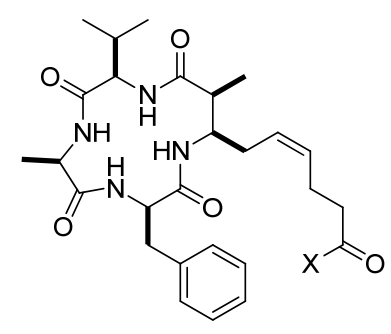

azumamide $\mathrm{A}, \mathrm{X}=\mathrm{NH}_{2}$ azumamide $\mathrm{E}, \mathrm{X}=\mathrm{OH}$<smiles>CCCC1CC2CCC[C@@H]3CCC[C@H](C1)N23</smiles>

(+)-porantheridine<smiles>CN(CC(=O)O)NC(=O)CC(N)C[C@H](O)CN</smiles>

(+)-negamycin

1,2-加成反应, Zafarian 课题组 ${ }^{[22 a-52 b]}$ 合成了 neodysidenin 和 sintokamides A, B, D, E; Ganesan 课题组 ${ }^{[52 c]}$ 合成了 azumamides A, E; Huang 课题组 ${ }^{[52 \mathrm{~d}]}$ 合成 $(+)$-porantheridine; Wolfe 课题组 ${ }^{[52 \mathrm{e}]}$ 合成了 merobatzelladine $\mathrm{B}$; 韩 世清课题组 ${ }^{[52 f]}$ 合成了 $(+)$-negamycin.

\section{2 叔丁基亚磺酰亚胺的还原}

2019 年, 齐湘兵课题组 ${ }^{[53]}$ 报道了(一)-alstofolinine $\mathrm{A}$ 的全合成. 作者通过对叔丁基亚磺酰亚胺的还原引入 关键的氮杂手性中心, 利用呋喃氧化重排和吲哚亲核加 成反应为核心策略构建出了天然产物骨架.

作者从化合物 169 出发, 与(S)-叔丁基亚磺酰胺缩 合得到叔丁基亚磺酰亚胺，经过 $(+)$-二异松蒎烯基硼烷 还原引入首个立体中心, 得到仲胺 170, $d r$ 值为 $20: 1$. $m$-CPBA 与化合物 $\mathbf{1 7 0}$ 作用后, 发生氧化重排及分子内 亲核加成得到化合物 171. 随后 171 经过氮上引入甲基、 还原双键、发生 Claisen 缩合及将羰基转化为烯醇 OTf 得到化合物 172 . 在零价钯促进下, 172 与三丁基锡甲 醇发生 Stille 偶联后，再发生分子内的酯化得到化合物 173. 最后 173 经过还原双键和氮原子上引入甲基得到 (一)-alstofolinine A (Scheme 27).

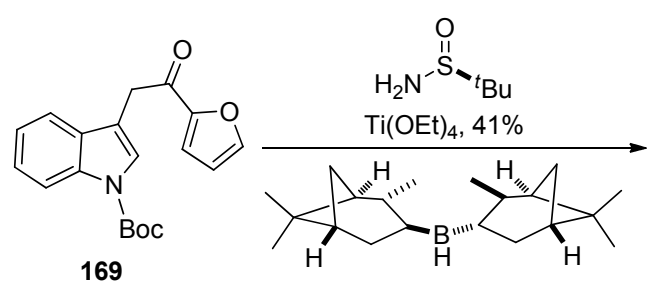

169

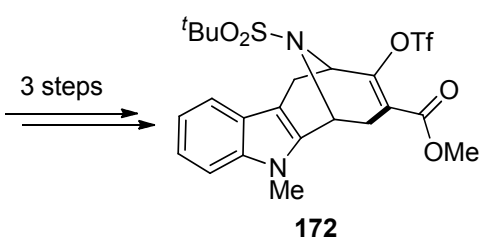<smiles>CS(=O)NC(Cc1cn(Cc2ccccc2)c2ccccc12)c1ccccc1</smiles>

(1) $m$-CPBA, $94 \%$ $\underset{\mathrm{MeCN} / \mathrm{H}_{2} \mathrm{O}(\mathrm{V}: \mathrm{V}=4: 1)}{\stackrel{\text { (2) } \mathrm{NBS}, \mathrm{AcONa} \cdot 3 \mathrm{H}_{2} \mathrm{O}}{\longrightarrow}}$ then silica gel $70 \%$

$170(20: 1 d r)$<smiles>CC(C)(C)OS(=O)N1Cc2c([nH]c3ccccc23)C2C=CC(=O)C1C2</smiles>

171<smiles>CC(C)(C)OS(=O)(=O)N1C2CCCC1c1c2[nH]c2ccccc12</smiles>

173

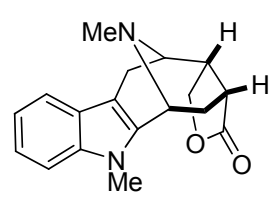

(-)-alstofolinine A

图式 27 齐湘兵课题组关于(一)-alstofolinine A 的全合成

Scheme 27 Total synthesis of ( - -alstofolinine A by Qi group 
作者通过手性的叔丁基亚磺酰亚胺的还原得到手

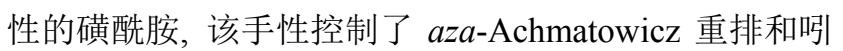
哚亲核环化反应的立体化学, 生成单一的氮杂双环 [3.3.1]壬烷骨架化合物, 为不对称合成氮杂双环 [3.3.1] 壬烷骨架的天然产物提供了一种高效的方法.

应用叔丁基亚磺酰亚胺的还原引入手性中心合成 的天然产物的例子还包括李闯创课题组 ${ }^{[54 \mathrm{a}]}$ 合成的 $(+)-(a S, 7 R)$-colchicine、Ryan 课题组 ${ }^{[54 b]}$ 合成的 mexiletine 和周伟澄课题组 ${ }^{[44]}$ 合成的 maravrioc.
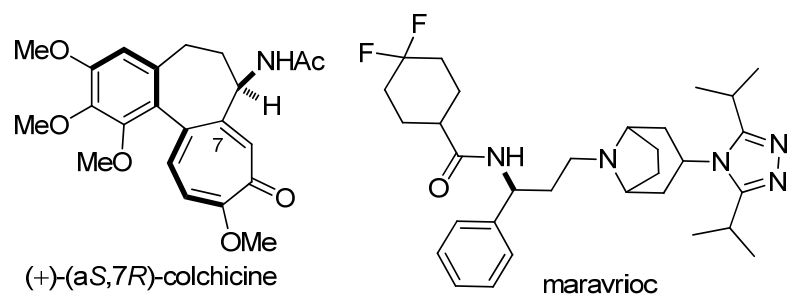<smiles>Cc1cccc(C)c1OC[C@H](C)Cl</smiles>

\section{$1.3 \mathrm{Sml}_{2}$ 促进的叔丁基亚磺酰亚胺的还原偶联反应}

2005 年, 林国强课题组 ${ }^{[55]}$ 发展了 $\mathrm{SmI}_{2}$ 促进的叔丁 基亚磺酰亚胺与醛的还原偶联反应. 他们将该方法应用 于 $D$-erythro-sphinganine 的全合成.

作者以手性的叔丁基亚磺酰亚胺 175 与正十六醛 (174)为原料, 在 $\mathrm{SmI}_{2}$ 作用下高立体选择性地实现了还 原偶联得到 $\beta$-氨基醇 176. 接着在锂/萗和盐酸条件下分 别脱除苄基和亚磺酰基得到 $D$-erythro-sphinganine. 这 是已知的该化合物最简洁的合成方法. 同时他们也合成 了 $(3 R, 4 S)$-statine (Scheme 28).

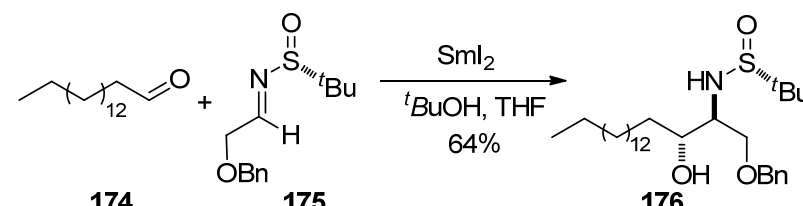

174

175 176<smiles></smiles><smiles>CC(C)C(N)C(O)CC(=O)O</smiles>

图式 28 林国强课题组关于 $D$-erythro-sphinganine 的全合成 Scheme 28 Total synthesis of $D$-erythro-sphinganine by Lin group

作者开发了一种高效且实用的合成手性 $\beta$-氨基醇 的方法，这种方法对于手性 $\beta$-氨基醇化合物的制备是非 常高效的. 该方法在天然产物的不对称合成中应该会取 得更广泛的应用.

2009 年, 林国强课题组 ${ }^{[56]}$ 报道了(+)-febrifugine 的 不对称合成. 关键步骤为 $\mathrm{SmI}_{2}$ 促进的手性叔丁基亚磺 酰亚胺与醛的还原偶联构建 $\beta$-氨基醇.

作者从化合物 177 出发, 经过 Swern 氧化, 生成的 醛与叔丁基亚磺酰胺缩合得到化合物 178. 醛基化合物 179 与叔丁基亚磺酰亚胺 178 在二碘化钐促进下发生还 原偶联反应得到 $\beta$-氨基醇 180, $d r$ 值为 $93.5: 4.0 ： 2.0$ : 0.5. 化合物 180 经过两步氮和氧原子上的保护基修饰得 到化合物 181, TBAF 脱除伯醇硅保护基后将其活化为甲 磺酸酯，再在 $\mathrm{NaH}$ 作用下发生分子内氮烷基化反应生 成化合物 182 . 化合物 182 经过 3 步转化将邻二醇结构 转化为环氧得到化合物 183 , 随后与 4-喹唑酮钾盐反应 发生环氧开环生成化合物 184. 化合物 184 经过二级醇 的氧化及氮上保护基的脱除可以转化为天然产物 $(+)$-febrifugine (Scheme 29).

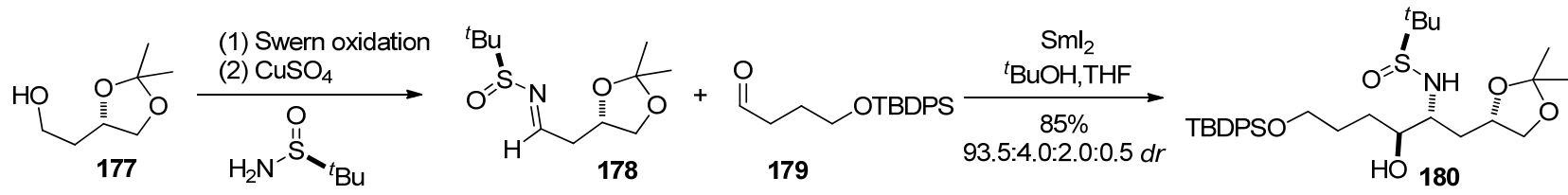

$85 \%$ (2 steps)

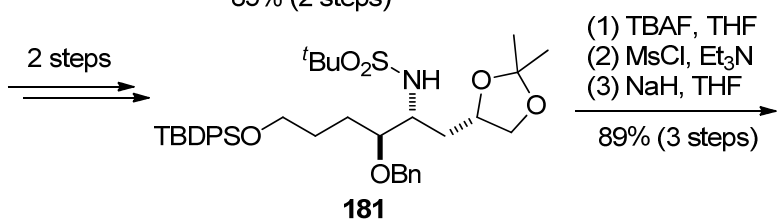

181
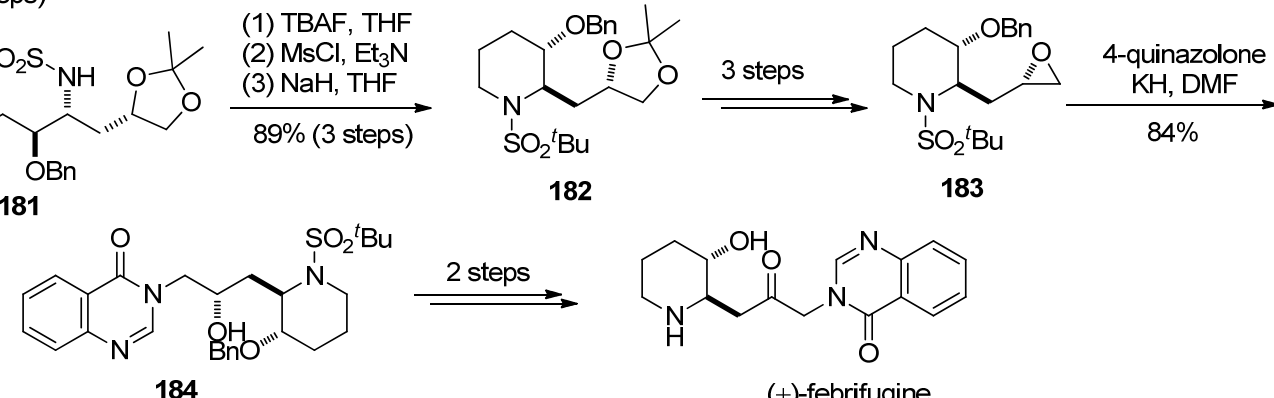

(+)-febrifugine

图式 29 林国强课题组关于 (+)-febrifugine 的不对称合成

Scheme 29 Asymmetric synthesis of $(+)$-febrifugine by Lin group 
作者发展的 $\mathrm{SmI}_{2}$ 促进的叔丁基亚磺酰亚胺与 $\gamma$-羟 基醛衍生物的还原偶联, 为 3-羟基取代的哌啶骨架的不 对称合成提供了一种高效的方法.

2016 年, 魏邦国课题组 ${ }^{[57]}$ 报道了对 epohelmin A 的 不对称全合成. 作者利用手性叔丁基亚磺酰亚胺在 $\mathrm{SmI}_{2}$ 条件下与醛的还原偶联, 构建 $\beta$-氨基醇.

他们以醛 185 和叔丁基亚磺酰亚胺 186 为原料, 经 过还原偶联得到 $\beta$-氨基醇 187. 化合物 187 经过三步保 护基的转化得到化合物 188, 再经过 3 步转化延长碳链 得到化合物 189. 接下来化合物 189 与甲基膦酸酯加成 得到化合物 190. 化合物 190 脱除 PMB 保护基以后，与 己醛发生 Horner-Wadsworth-Emmons 反应生成化合物 191. 用 $\mathrm{MsCl}$ 活化差基, 脱除 $\mathrm{Boc}$ 基团后发生分子内双 氮烷基化反应，最后脱除硅基可以得到 epohelmin A. 同 时该小组也合成了 epohelmin B (Scheme 30).

另外, 利用此还原偶联方法, 林国强课题组还合成 了 $\left(\right.$ 一)-deoxoprosophylline ${ }^{[58 \mathrm{a}]}$; 魏邦国课题组合成了 D-ribo-phytosphingosine 和 dolastatin $10^{[58 b, 58 c]}$.

\section{2 叔丁基亚磺酰基金属烯胺与亲电试剂的加成 反应}

叔丁基亚磺酰亚胺转化为叔丁基亚磺酰基金属烯 胺以后, 可以与亲电试剂反应, 立体选择性地生成新的 化学键. 相比于叔丁基亚磺酰亚胺的 1,2-加成反应诱导 胺的 $\alpha$ 位立体中心的生成, 叔基亚磺酰基金属烯胺与亲 电试剂的加成反应可以诱导胺的 $\beta$ 位立体中心的生成.
反应过程中新产生的叔丁基亚磺酰亚胺可以继续发生 1,2-加成反应构建胺的 $\alpha$ 位立体中心，进而得到含有 $\alpha$ 和 $\beta$ 两个手性中心手性胺类化合物.

2004 年, Ellman 课题组 ${ }^{[59]}$ 报道了手性叔丁基亚磺酰 亚胺的高立体选择性 $\alpha$-烷基化反应. 作者利用该方法引 入 $\mathrm{C}(6)$ 位立体中心, 最终实现了天然产物 (6R,7S)-7amino-7,8-dihydro- $\alpha$-bisabolene 的首次不对称合成.

以原酸酯 192 和 $(R)$-叔丁基亚磺酰胺为原料, 在 $\mathrm{MgSO}_{4}$ 作用下进行缩合后，再与 $\mathrm{NaI}$ 发生卤素交换生成 碘代物，在异丙烯基溴化镁及 $\mathrm{CuI}$ 条件下发生偶联反应， 得到化合物 193. 化合物 193 和吗啡啉在催化量的 $\mathrm{NaCN}$ 作用下反应得到 194, 在六甲基二硅氨基钾(KHMDS)条 件下发生去质子化生成金属烯胺，再与烯丙基溴发生烷 基化引入 $\mathrm{C}(6)$ 位手性中心, 生成单一的非对映异构体 195. 化合物 195 与甲基铈试剂发生加成反应，再经过 RCM 反应生成环已烯 196. 化合物 196 和锂试剂 197 发 生亲核加成反应生成单一的非对映异构体产物, 实现 $\mathrm{C}(7)$ 位氮杂季碳手性中心的构建. 最后脱除叔丁基亚磺 酰 基 合 成 (6R,7S)-7-amino-7,8-dihydro- $\alpha$-bisabolene (Scheme 31).

Ellman 课题组发展了一种在手性叔丁基亚磺酰亚 胺的 $\alpha$ 位引入手性烷基链的反应, 并且利用新生成的叔 丁基亚磺酰亚胺参与后续的 1,2-加成反应，该方法可以 应用于包含 $\alpha$ 和 $\beta$ 手性中心的胺的合成, 为连续手性中 心的构建提供了一种高效的方法.
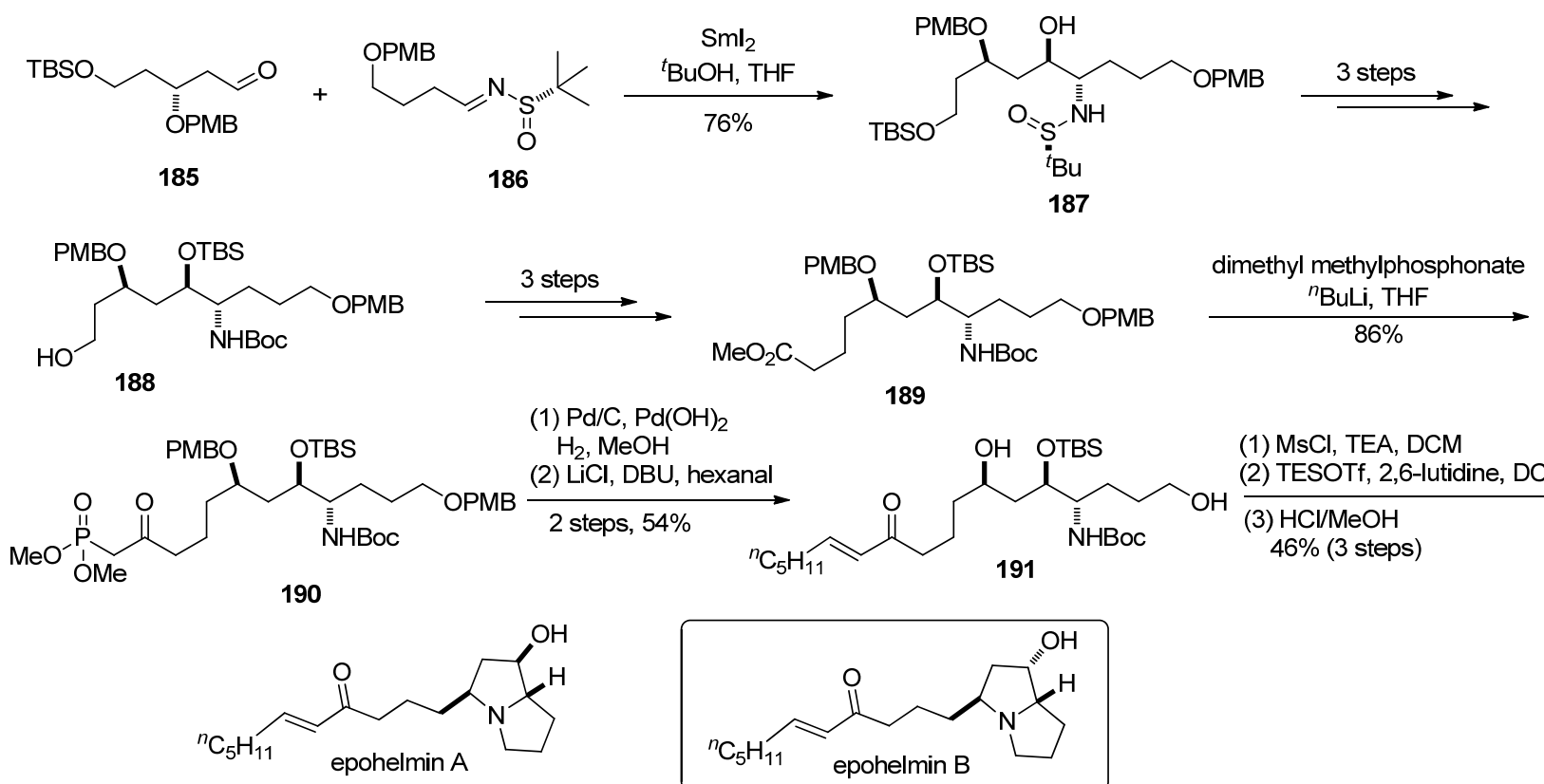

189

$\mathrm{H}_{2}, \mathrm{MeOH}$

(2) $\mathrm{LiCl}, \mathrm{DBU}$, hexanal

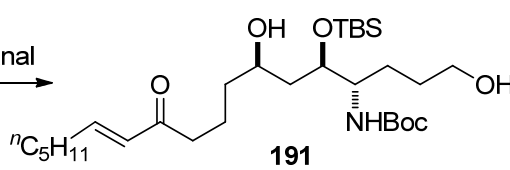

(1) $\mathrm{MsCl}, \mathrm{TEA}, \mathrm{DCM}$

(2) TESOTf, 2,6-lutidine, DCM

steps, $54 \%$

(3) $\mathrm{HCl} / \mathrm{MeOH}$

$46 \%$ (3 steps)

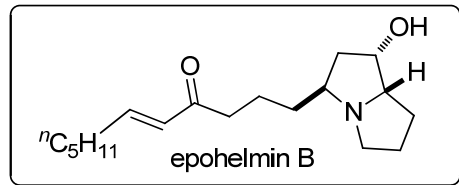

图式 30 魏邦国课题组关于 epohelmin A 的不对称合成

Scheme 30 Asymmetric synthesis of epohelmin A by Wei group 
<smiles>CCCCCCCCCCCCCO</smiles>

(-)-deoxoprosophylline<smiles>CCCCCCC(O)C(O)C(N)CO</smiles>

D-ribo-phytosphingosine

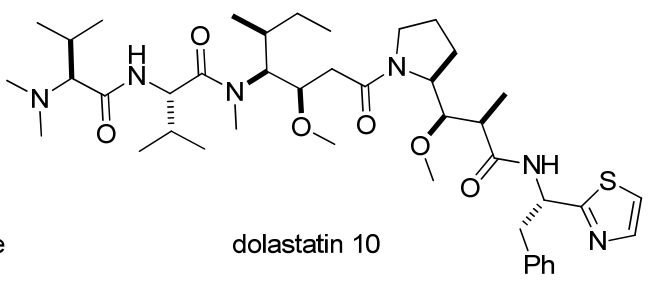

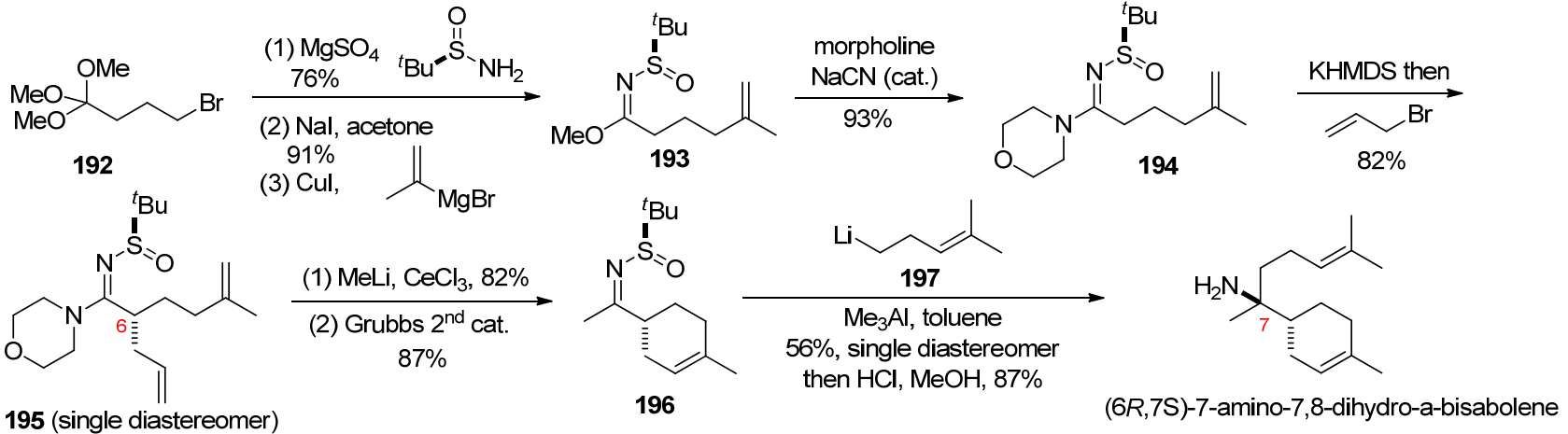

图式 31 Ellman 课题组关于 $(6 R, 7 S)$-7-amino-7,8-dihydro- $\alpha$-bisabolene 的合成

Scheme 31 Total synthesis of $(6 R, 7 S)$-7-amino-7,8-dihydro- $\alpha$-bisabolene by Ellman group

2006 年, Ellman 课题组 ${ }^{[60]}$ 利用叔丁基亚磺酰胺参与 的不对称加成反应完成了 tubulysin D 的首次全合成. Tubulysin $\mathrm{D}$ 的结构可以分为 4 个氨基酸片段: (2R)- $N$-甲 基-2-哌啶甲酸(Mep)、异亮氨酸(Ile)、tubuvaline (Tuv) 和 tubuphenylalanine (Tup).

Tup 片段的合成以苯乙醛(198)为原料，与(R)-叔丁 基亚磺酰胺缩合生成叔丁基亚磺酰亚胺 199, 再在 $\mathrm{SmI}_{2}$ 促进下与 2-甲基丙烯酸甲酯 $\mathbf{2 0 0}$ 发生还原偶联反应，引 入 2 个立体中心得到化合物 201, 酸解脱除亚磺酰基生 成胺盐酸盐 Tup (202). 对于 tubulysin D 的合成, 在 LDA 条件下, $(S)$-叔丁基亚磺酰酮亚胺 203 去质子化生成叔丁 基亚磺酰基金属烯胺, 然后与噻唑啉醛 204 发生不对称 加成反应引入亚胺的 $\beta$ 位立体中心, 生成化合物 $\mathbf{2 0 5}, d r$ 值为 $92: 8$. 用 $\mathrm{NaBH}_{4}$ 立体选择性还原亚胺 $205, d r$ 值为 91：1, 在酸性条件下生成 1,3-氨基酸盐酸盐 Tuv (206). Tuv (206) 和 $\alpha$-叠氮酰氯 207 发生酰胺化反应, 用三乙基 硅基(TES)保护仲醇, 氮烷基化引入侧链, 生成叠氮化 合物 208. 在 $\mathrm{Pd} / \mathrm{C}$ 及 $\mathrm{H}_{2}$ 条件下还原化合物 208 中的叠 氮后, 与五氟苯酚活化的 Mep 酯发生胺解, 接着脱除 TES 保护基, $\mathrm{Me}_{3} \mathrm{SnOH}$ 水解甲酯 ${ }^{[61]}$ 得到羧酸 209. 氟苯 酚活化着酸 209 后, 与 Tup (202)发生胺解, 最后乙酰化 合成 tubulysin D (Scheme 32).

作者采用手性叔丁基亚磺酰胺的高立体选择性反 应构建了 tubulysin D 结构中的四个手性中心并完成了 tubulysin D 的首次不对称全合成, 同时报道了首例亚胺 和不饱和羰基化合物的不对称偶联反应.

2013 年, Andrade 课题组 ${ }^{[62]}$ 报道了 aspidosperma 生 物碱( $(-)$-aspidospermidine, (-)-tabersonine 和(一)-vin- cadifformine 的不对称全合成. 他们利用叔丁基亚磺酰 亚胺与不饱和酯发生串联 Michael/Mannich/氮烷基化反 应一步构建两个立体中心, 并形成 $\mathrm{E}$ 环; 通过 RCM 反 应构建 D 环, Bosch-Rubiralta 螺环化反应构建 C 环.

以醛 210 为原料, 在 $\mathrm{Ti}(\mathrm{OEt})_{4}$ 作用下与 $(S)$-叔丁基亚 磺酰胺缩合生成叔丁基亚磺酰亚胺 211. 化合物 211 在 LiHMDS 作用下发生去质子化，生成叔丁基亚磺酰基金 属烯胺中间体，再与 2-乙基丙烯酸酯 212 发生 Michael 加成反应形成烯醇化物, 然后发生分子内 Mannich 反应 构建 $\mathrm{E}$ 环, 最后加入烯丙基溴淬灭反应, 发生氮烷基化 生成四氢咔唑化合物 213, $d r$ 值为 $11: 1$. 化合物 213 经 过 3 步转化将 $\mathrm{C}(5)$ 酯基转化为乙烯基, 得到化合物 214, 然后在第二代 Grubbs 催化剂的催化下发生 RCM 反应得 到四环化合物 215, 再经过 2 步转化生成化合物 216. 在 $t$-BuOK 条件下, 化合物 $\mathbf{2 1 6}$ 发生 Bosch-Rubiralta 螺环化 反应构建 C 环得到五环骨架化合物. 在 LDA 作用下, 217 生成金属烯胺, 再经 Mander 试剂淬灭即可得到 (-)-tabersonine. 在 Adams 催化剂的催化下进行氢化可 以将(-)-tabersonine 转化为(-)-vincadifformine. 另外, 化合物 217 经过氢化可以合成天然产物(一)-aspidospermidine (Scheme 33).

Andrade 课题组发展了手性叔丁基亚磺酰亚胺到烯 胺的转化, 并实现了串联 Michael/Mannich/氮烷基化反 应构建连续的手性中心的新方法.

2015 年, 秦勇课题组 ${ }^{[63]}$ 报道了(一)-2-hydroxyisoschizogamine 及 isoschizogamine 的全合成，他们通过叔 丁基亚磺酰胺衍生物对不饱和酯基化合物的加成构建 了第一个关键的手性中心. 


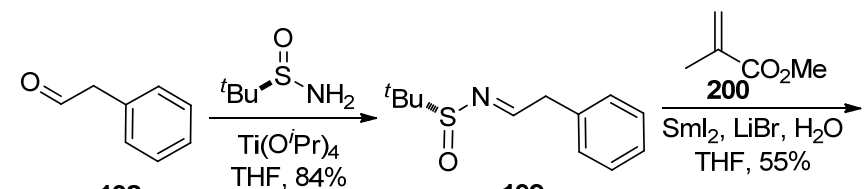

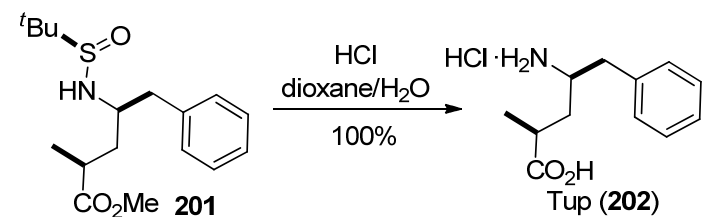

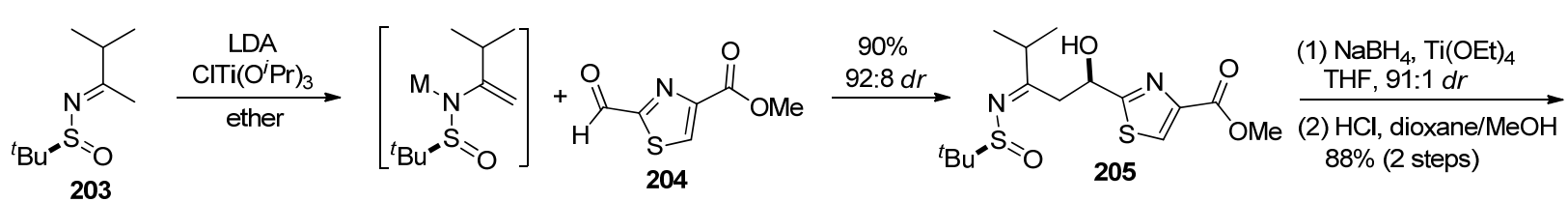

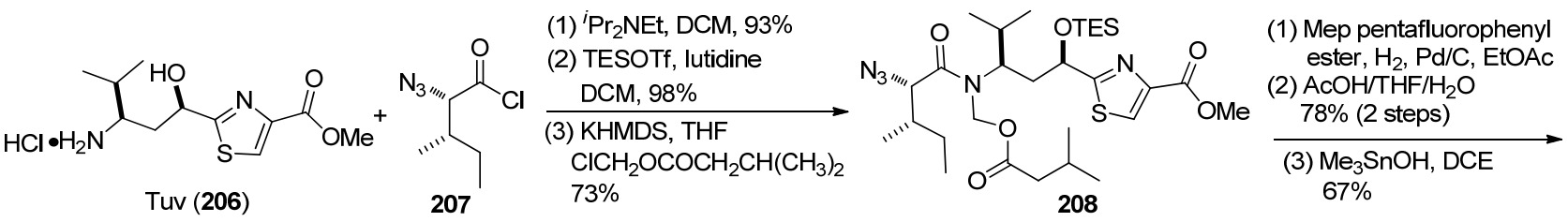<smiles>CC(C)CC(=O)OCN(C(=O)[C@@H](NC(=O)C1CCCCN1C)C(C)C)C(CC(O)c1nc(C(=O)O)cs1)C(C)C</smiles>

图式 32 Ellman 课题组关于 tubulysin D 的全合成

Scheme 32 Total synthesis of tubulysin D by Ellman group

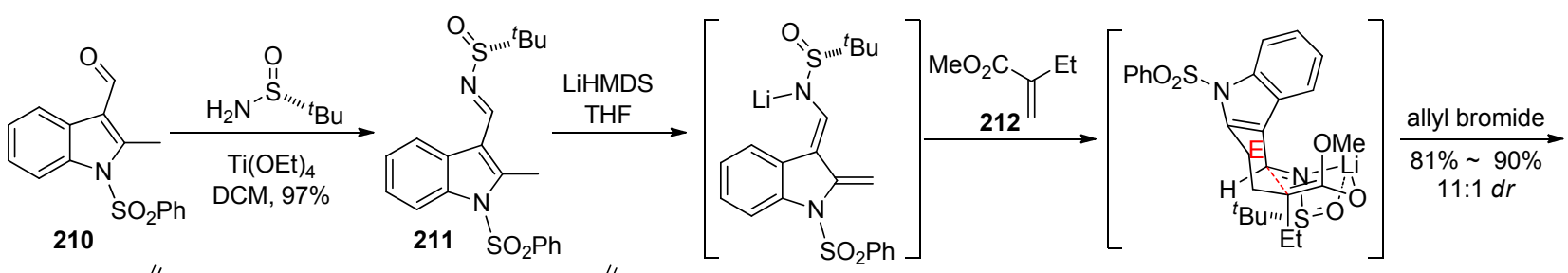

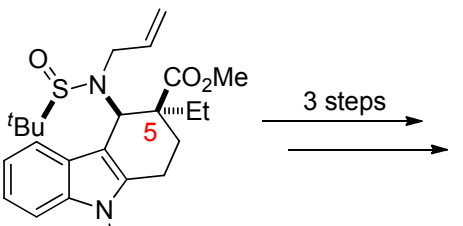

$213 \mathrm{SO}_{2} \mathrm{Ph}$

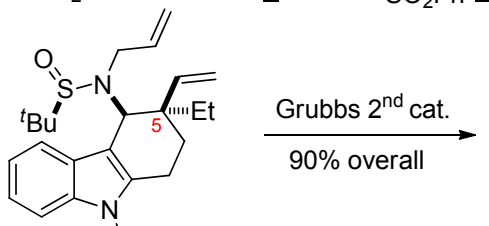

$214 \mathrm{SO}_{2} \mathrm{Ph}$

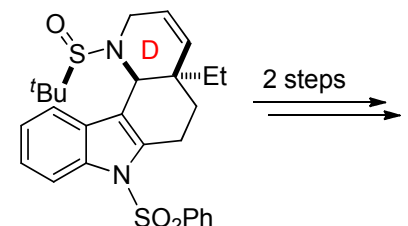

215

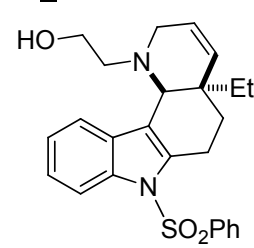

216

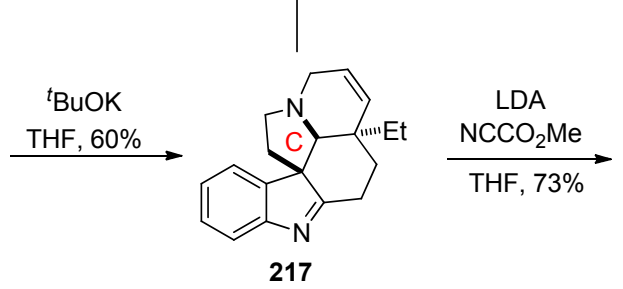

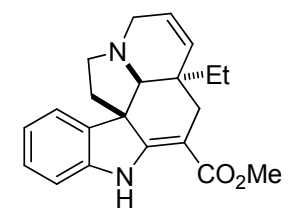

(-)-tabersonine

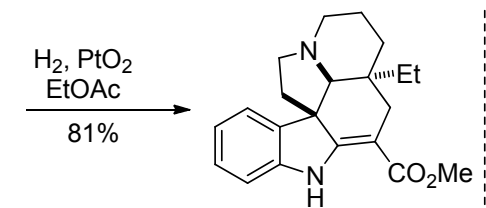

(-)-vincadiifformine<smiles>CCC12CCCN3CCC4(c5ccccc5NC14)C3C2</smiles>

(-)-aspidospermidine

图式 33 Andrade 课题组关于 $(-)$-aspidospermidine, ( - -tabersonine 和(一)-vincadifformine 的全合成

Scheme 33 Total synthesis of $(-)$-aspidospermidine, $(-)$-tabersonine and ( $(-)$-vincadifformine by Andrade group

叔丁基亚磺酰亚胺 $\mathbf{2 1 8}$ 在 LiHMDS 作用下发生去质 子化，生成叔丁基亚磺酰基金属烯胺中间体，再与二酯 化合物 219 发生 Michael 加成反应, 引入 C(7)位手性中 心, 生成化合物 220, $d r$ 值为 $5:$ 1. 使用嗍烷还原亚胺同 时实现脱氧可以将 220 转化为 221 , 经过后续 6 步转化
构建 B 环，得到化合物 222. 化合物 222 在三氟甲磺酸 的作用下脱去氨基上的保护基，同时与酮羰基缩合形成 烯胺结构, 完成 $\mathrm{C}$ 环的构建, 得到化合物 223. 在 $\mathrm{NaH}$ 作用下化合物 223 与不饱和炔酮发生 Michael 加成反应 引入 $\mathrm{C}(20)$ 位手性, 之后进行酰胺化实现 $\mathrm{D}$ 环的构建, 
得到化合物 224. 此过程中 $\mathrm{C}(7)$ 位的立体中心很好地诱 导了 C(20)位季碳手性中心的生成. 224 经过七步官能团 转化得到化合物 225, 在 Meerwin 试剂作用下将酰胺异 构为亚胺, 自发进行环化反应然后进行还原, 得到天然 产物的骨架化合物 226, 最后进行 4 步官能团转化可以 得到 $(-)$-2-hydroxyisoschizogamine 及 $(-)$-isoschizogamine (Scheme 34).

秦勇课题组通过叔丁基亚磺酰亚胺生成的金属烯胺 与不饱和二酯化合物的不对称 Michael 加成反应，引入 C(7)位立体中心. 该立体中心很好地诱导了 C(20)位季碳 手性的构建, 为不对称合成 $(-)$-2-hydroxyisoschizogamine 和(-)-2-hydroxyisoschizogamine 奠定了基础.

2019 年, Andrade 课题组 ${ }^{[64]}$ 应用组内发展的叔丁基 亚磺酰亚胺与不饱和酯发生串联 Michael/Mannich 环化
反应 ${ }^{[62]}$, 引入了三个连续的手性中心，该立体中心诱导 了后续螺环化反应生成新的立体中心，进而完成了 $(+)$-epi-condyfoline 的首次全合成.

他们从简单易得的叔丁基亚磺酰亚胺 227 出发, 在 LiHMDS 作用下拔氢形成叔丁基亚磺酰基金属烯胺，再 与内酯 228 发生串联 Michael/Mannich 环化反应实现三 个连续立体中心的构建, 生成四环内酯 $\mathbf{2 2 9}, d r$ 值为 6.5：1. 化合物 229 经过 2 步转化得到化合物 230, 再在 LiHMDS 条件下发生分子内 $\mathrm{S}_{\mathrm{N}} 2$ 反应构建哌啶环，得到 化合物 231. 化合物 231 经过 6 步官能团转化得到 232, 接着在 DMTSF (233)作用下发生螺环化反应 ${ }^{[65]}$ 构建吡 咯环, 生成五环骨架化合物 $\mathbf{2 3 4}$, 最后经过 2 步氧化态 的调整完成了 $(+)$-epi-condyfoline 的全合成(Scheme 35).

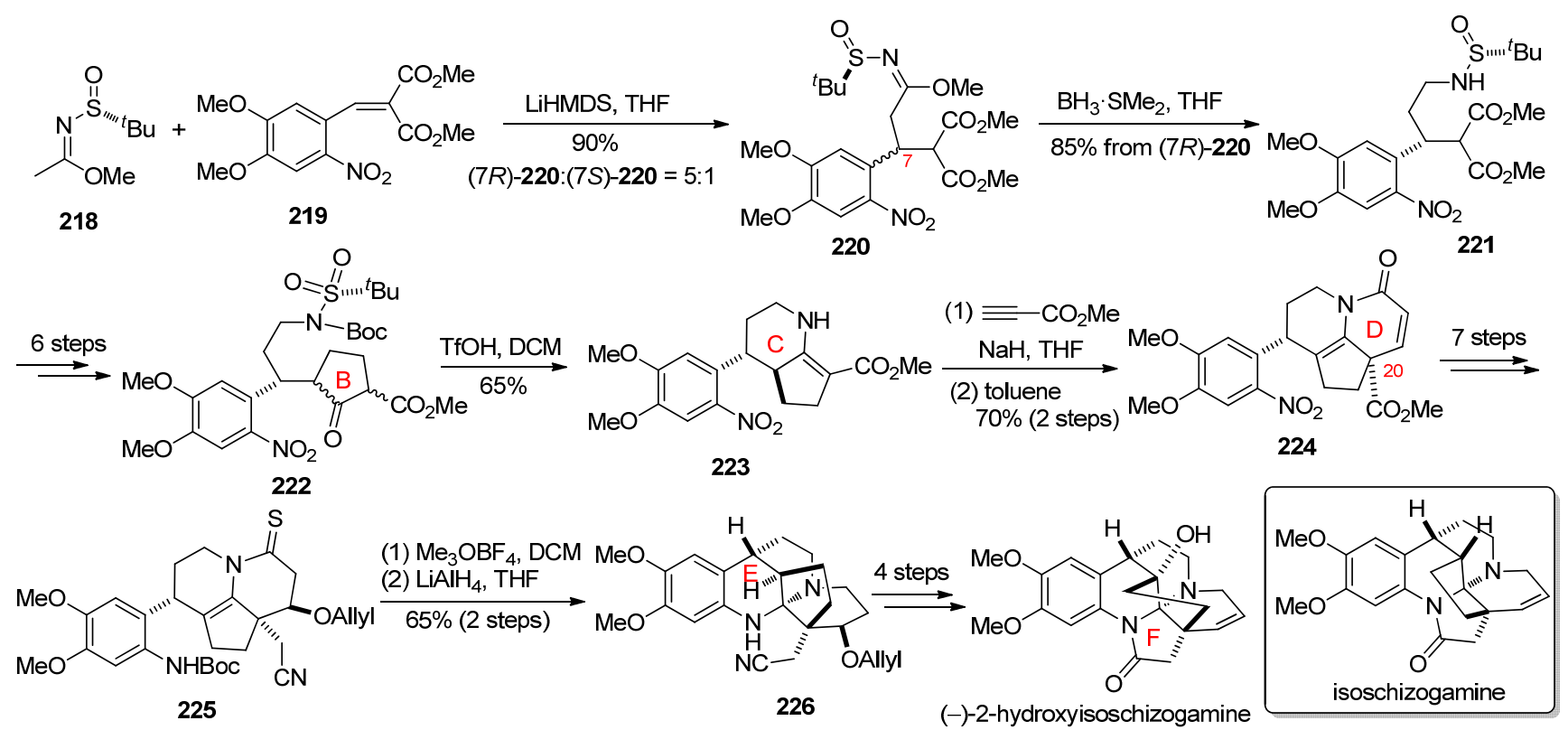

图式 34 秦勇课题组关于(一)-2-hydroxyisoschizogamine 和 isoschizogamine 的全合成

Scheme 34 Total synthesis of (-)-2-hydroxyisoschizogamine and isoschizogamine by Qin and co-workers

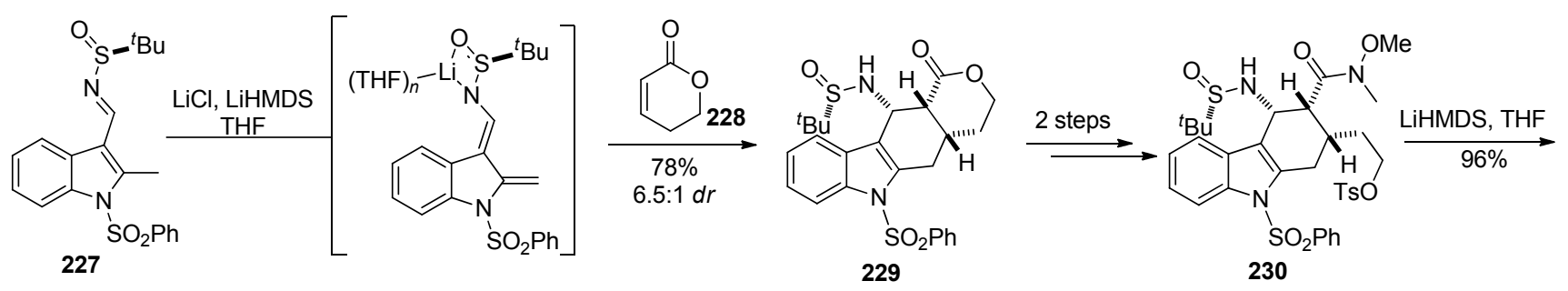

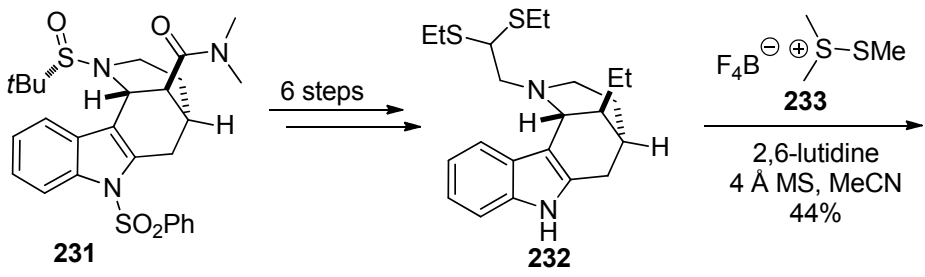

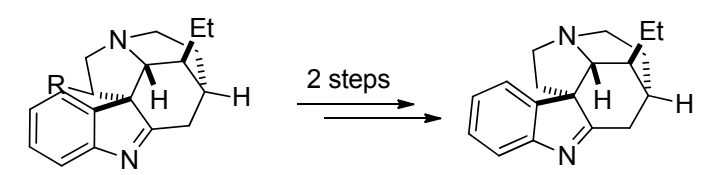

$234 \mathrm{R}=\mathrm{SEt}$

图式 35 Andrade 课题组关于 $(+)$-epi-condyfoline 的全合成

Scheme 35 Total synthesis of $(+)$-epi-condyfoline by Andrade group 
作者报道的手性叔丁基亚磺酰基金属烯胺发生串 联 Michael/Mannich 环化反应, 为合成包含四氢- $\beta$-咔啉 骨架的天然产物提供了新的思路.

叔丁基亚磺酰基金属烯胺与亲电试剂的加成反应 合成天然产物的例子还包括 Suna 课题组 ${ }^{[66 a]}$ 合成的 $(-)$-14-epi-pseudotabersonine 和 $(+)$-pseudotabersonine 以及 Floreancig 课题组 ${ }^{[66 b]}$ 合成的(-)-andrachcinidine.
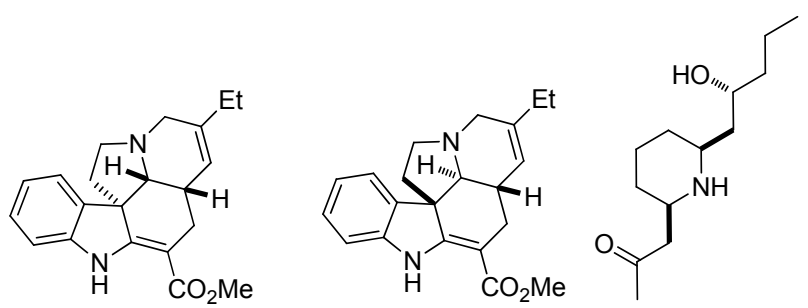

(+)-pseudotabersonine (-)-14-epi-pseudotabersonine andrachcinidine

\section{3 结论与展望}

综上所述, 以叔丁基亚磺酰胺为手性辅基诱导 生成立体中心，在天然产物全合成中具有广泛的应 用。该策略在全合成中的应用大都可以以较好的立 体选择性得到期望的手性中心. 该反应常应用于构 建天然产物中的叔碳手性中心, 而构建季碳手性中 心的例子相对较少. 所以其在氮杂季碳手性中心的 构建及相应的天然产物合成研究方面还需进一步拓 展. 目前发现的包含氮杂季碳手性中心的天然产物 极为丰富, 如 erythrina, hasubanan, acutumine 和 ecteinascidins 等生物碱, 期望将来有更多叔丁基亚磺 酰胺在含有氮杂季碳手性中心的天然产物全合成中 的应用报道.

\section{References}

[1] Liu, G.; Cogan, D. A.; Ellman, J. A. J. Am. Chem. Soc. 1997, 119, 9913.

[2] (a) Ellman, J. A.; Owens, T. D.; Tang, T. P. Acc. Chem. Res. 2002, 35,984 .

(b) Ellman, J. A. Pure Appl. Chem. 2003, 75, 39.

(c) Lin, G. Q.; Xu, M. H.; Zhong, Y. W.; Sun, X. W. Acc. Chem. Res. 2008, $41,831$.

(d) Ferreira, F.; Botuha, C.; Chemla, F.; Pérez-Luna, A. Chem. Soc. Rev. 2009, 38, 1162

(e) Robak, M. T.; Herbage, M. A.; Ellman, J. A. Chem. Rev. 2010, 11,3600 .

(f) Liu, Q.; Hou, W. F.; Jing, Y. R.; Zhou, W.; Zhao, X. J. Prog. Pharm. Sci. 2013, 37, 493 (in Chinese).

(刘强, 侯文峰, 景云荣, 周微, 赵小军, 药学进展, 2013, 37, 493.)

(g) Zhu, Y. J.; Huan,Y. L.; Leng, W. D.; Wu, C. X.; Wang, B. Chin. J. Pharm. 2017, 48, 621 (in Chinese).

(朱怡君, 宦玉亮, 冷卫东, 伍成祥, 王兵, 中国医药工业杂志, 2017, 48, 621.)

[3] (a) Kochi, T.; Tang, T. P.; Ellman, J. A. J. Am. Chem. Soc. 2002, $124,6518$.

(b) Kochi, T.; Tang, T. P.; Ellman, J. A. J. Am. Chem. Soc. 2003,
$125,11276$.

[4] Xu, H. C.; Chowdhury, S.; Ellman, J. A. Nat. Protoc. 2013, 8, 2271.

[5] Kościołowicz, A.; Rozwadowska, M. D. Tetrahedron: Asymmetry 2006, 17, 1444.

[6] Si, C.-M.; Mao, Z.-Y.; Dong, H.-Q.; Du, Z.-T.; Wei, B.-G.; Lin, G.-Q. J. Org. Chem. 2015, 80, 5824.

[7] Si, C.-M.; Mao, Z.-Y.; Liu, Y.-W.; Du, Z.-T.; Wei, B.-G.; Lin, G.-Q. Org. Chem. Front. 2015, 2, 1485.

[8] Kiemele, E. R.; Wathier, M.; Bichler, P.; Love, J. A. Org. Lett. 2016, $18,492$.

[9] Pinto, A.; Griera, R.; Molins, E.; Fernández, I.; Bosch, J.; Amat, M. Org. Lett. 2017, 19, 1714.

[10] Pinto, A.; Piccichè, M.; Griera, R.; Molins, E.; Bosch, J.; Amat, M. J. Org. Chem. 2018, 83, 8364.

[11] Taghizadeh, M. J.; Gohari, S. J. A.; Javidan, A.; Moghimi, A.; Iman, M. J. Iran. Chem. Soc. 2018, 15, 2175.

[12] (a) Fustero, S.; Monteagudo, S.; Sánchez-Roselló, M.; Flores, S.; Barrio, P.; del Pozo, C. Chem.-Eur. J. 2010, 16, 9835.

(b) Shen, X., Zhao; J., Xi, Y.; Chen, W.; Zhou, Y.; Yang, X.; Zhang, H. J. Org. Chem. 2018, 83, 14507.

(c) Prasad, K. R.; Rangari, V. A. Tetrahedron 2019, 75, 130496 (d) Del Castillo, E.; Muñiz, K. Org. Lett. 2019, 21, 705.

[13] Chuang, K. V.; Navarro, R.; Reisman, S. E. Chem. Sci. 2011, 2, 1086.

[14] Toop, H. D.; Brusnahan, J. S.; Morris, J. C. Angew. Chem., Int. Ed. 2017, 56, 8536 .

[15] Liu, H. J.; Shia, K. S.; Shang, X.; Zhu, B. Y. Tetrahedron 1999, 55, 3803.

[16] Uphade, M. B.; Reddy, A. A.; Khandare, S. P.; Prasad, K. R. Org. Lett. 2019, 21, 9109.

[17] Wang, Y.; He, Q. F.; Wang, H. W.; Zhou, X.; Huang, Z. Y.; Qin, Y. J. Org. Chem. 2006, 71, 1588.

[18] Chogii, I.; Njardarson, J. T. Angew. Chem., Int. Ed. 2015, 54, 13706

[19] Chen, W.; Yang, X.; Tan, W.; Zhang, X.; Liao, X.; Zhang, H. Angew. Chem., Int. Ed. 2017, 56, 12327.

[20] Chen, W.; Ren, J.; Wang, M.; Dang, L.; Shen, X.; Yang, X.; Zhang, H. Chem. Commun. 2014, 50, 6259.

[21] (a) Zhang, S. X.; Shen, X. L.; Li, Z. Q.; Zou, L. W.; Wang, F. Q.; Zhang, H. B.; Shao, Z. H. J. Org. Chem. 2013, 78, 11444.

(b) Han-ya, Y.; Inui, T.; Yokoshima, S.; Tokuyama, H.; Fukuyama, T. Chem. Pharm. Bull. 2016, 64, 800.

[22] Kobayashi, S.; Ueda, T.; Fukuyama, T. Synlett 2000, 883.

[23] Al-Saffar, F. M.; Brown, R. C. D. Org. Lett. 2017, 19, 3502.

[24] Tang, T. P.; Ellman, J. A. J. Org. Chem. 2002, 67, 7819.

[25] (a) Cutter, A. C.; Miller, I. R.; Keily, J. F.; Bellingham, R. K.; Light, M. E.; Brown, R. C. Org. Lett. 2011, 13, 3988.

(b) Watkin, S. V.; Camp, N. P.; Brown, R. C. Org. Lett. 2013, 15, 4596.

[26] (a) Han, Z.; Krishnamurthy, D.; Senanayake, C. H. Org. Process Res. Dev. 2006, 10, 327 .

(b) Tian, M.; Yan, M.; Baran, P. S. J. Am. Chem. Soc. 2016, 138, 14234

(c) Wang, C.; Liu, Y. W.; Zhou, Z., Si; C. M., Sun, X.; Wei, B. G. Tetrahedron 2018, 74, 2158

(d) Hugelshofer, C. L.; Palani, V.; Sarpong, R. J. Am. Chem. Soc. 2019, 141, 8431.

[27] Brak, K.; Ellman, J. A. Org. Lett. 2010, 12, 2004.

[28] Cai, S. L.; Yuan, B. H.; Jiang, Y. X.; Lin, G. Q.; Sun, X. W. Chem. Commun. 2017, 53, 3520.

[29] Chen, Y.-J.; Cai, S.-L.; Wang, C.-C.; Cheng, J.-D.; Kramer, S.; Sun, X.-W. Chem.-Asian J. 2017, 12, 1309.

[30] Voituriez, A.; Ferreira, F.; Perezluna, A.; Chemla, F. Org. Lett. 2007, 9, 470

[31] Huang, P. Q.; Guo, Z. Q.; Ruan, Y. P. Org. Lett. 2006, 8, 1435.

[32] (a) Voituriez, A.; Ferreira, F.; Chemla, F. J. Org. Chem. 2007, 72, 5358 .

(b) Louvel, J.; Botuha, C.; Chemla, F.; Demont, E.; Ferreira, F.; Pé- 
rez-Luna, A. Eur. J. Org. Chem. 2010, 2921.

(c) Louvel, J.; Chemla, F.; Demont, E.; Ferreira, F.; Pérez-una, A.; Voituriez, A. Adv. Synth. Catal. 2011, 353, 2137.

(d) Hélal, B.; Ferreira, F.; Botuha, C.; Chemla, F.; Perez-Luna, A. Synlett 2009, 3115.

[33] Mei, S.; Zhao, G. Eur. J. Org. Chem. 2010, 1660.

[34] Sirasani, G.; Andrade, R. B. Org. Lett. 2011, 13, 4736.

[35] González-Gómez, J. C.; Medjahdi, M.; Foubelo, F.; Yus, M. J. Org. Chem. 2010, 75, 6308

[36] Medjahdi, M.; González-Gómez, J. C.; Foubelo, F.; Yus, M. Eur. J. Org. Chem. 2011, 2230.

[37] (a) Bosque, I.; González-Gómez, J. C.; Guijarro, A.; Foubelo, F.; Yus, M. J. Org. Chem. 2012, 77, 10340.

(b) Anton-Torrecillas, C.; González-Gómez, J. C. Org. Biomol. Chem. 2014, 12, 7018.

[38] Bonazzi, S.; Cheng, B.; Wzorek, J. S.; Evans, D. A. J. Am. Chem. Soc. 2013, 135, 9338.

[39] Shen, A.; Liu, M.; Jia, Z. S.; Xu, M. H.; Lin, G. Q. Org. Lett. 2010, 12,5154 .

[40] Still, W. C.; Gennari, C. Tetrahedron Lett. 1983, 24, 4405.

[41] Zhao, S.; Sirasani, G.; Vaddypally, S.; Zdilla, M. J.; Andrade, R. B. Angew. Chem., Int. Ed. 2013, 52, 8309 .

[42] Davies, S. G.; Fletcher, A. M.; Roberts, P. M.; Shah, R. S.; Thompson, A. L.; Thomson, J. E. Org. Lett. 2014, 16, 1354.

[43] Davies, S. G.; Fletcher, A. M.; Shah, R. S.; Roberts, P. M.; Thomson, J. E. J. Org. Chem. 2015, 80, 4017.

[44] Ye, J.; Zhang, Y.; Liu, Y.; Zhang, J.; Ruan, Y.; Huang, P. Org. Chem Front. 2015, 2, 697.

[45] (a) Guo, L. D.; Liang, P.; Zheng, J. F.; Huang, P. Q. Eur. J. Org. Chem. 2013, 2230.

(b) Ye, J. L.; Chen, H.; Zhang, Y. F.; Huang, P. Q. Org. Chem. Front. 2016, 3, 683.

[46] Cai, S. L.; Song, R.; Dong, H. Q.; Lin, G. Q.; Sun, X. W. Org. Lett. 2016, 18, 1996

[47] Liu, H.; Zhang, X.; Shan, D.; Pitchakuntla, M.; Ma, Y.; Jia, Y. Org. Lett. 2017, 19, 3323.

[48] Larock, R. C.; Yum, E. K.; Refvik, M. D. J. Org. Chem. 1998, 63, 7652 .

[49] (a) Botuha, C.; Chemla, F.; Ferreira, F.; Perez Luna, A.; Roy, B. New J. Chem. 2007, 31, 1552.

(b) Chemla, F.; Ferreira, F.; Gaucher, X.; Palais, L. Synthesis 2007, 1235 . (c) Chemla, F.; Ferreira, F. Synlett 2006, 2613.

[50] Schkeryantz, J. M.; Woo, J. C. G.; Siliphaivanh, P.; Depew, K. M.; Danishefsky, S. J. J. Am. Chem. Soc. 1999, 121, 11964.

[51] Bonazzi, S.; Cheng, B.; Wzorek, J. S.; Evans, D. A. J. Am. Chem. Soc. 2013, 135, 9338
[52] (a) Beaumont, S.; Ilardi, E. A.; Monroe, L. R.; Zakarian, A. J. Am. Chem. Soc. 2010, 132, 1482.

(b) Gu, Z.; Zakarian, A. Angew. Chem., Int. Ed. 2010, 49, 9702.

(c) Wen, S.; Carey, K. L.; Nakao, Y.; Fusetani, N.; Packham, G.; Ganesan, A. Org. Lett. 2007, 9, 1105.

(d) Wang, J.; Li, W.; Liu, L.; Wang, B.; Zhou, Y.; Huang, S.; Wang, X. Org. Chem. Front. 2019, 6, 1599.

(e) Babij, N. R.; Wolfe, J. P. Angew. Chem., Int. Ed. 2012, 51, 4128.

(f) Zhang, S.-J.; Li, X.-T.; Wang, Y.; Zheng, Y.-C.; Han, S.-Q.; Yu, H.-L.; Huang, S.-H. Chin. J. Org. Chem. 2020, 40, 521 (in Chinese).

(张世举，李晓形，王燕，郑宇璁，韩世清，郁惠蕾，黄莎华，有 机化学, 2020, 40, 521.)

[53] Zhang, L.; Zhang, Y.; Li, W.; Qi, X. Angew. Chem., Int. Ed. 2019, $58,4988$.

[54] (a) Chen, B.; Liu, X.; Hu, Y.-J.; Zhang, D.-M.; Deng, L.; Lu, J.; Min, L.; Ye, W.-C.; Li, C.-C. Chem. Sci. 2017, 8, 4961.

(b) Ryan, D. A.; Okolotowicz, K. J.; Mercola, M.; Cashman, J. R. Tetrahedron Lett. 2015, 56, 4195.

(c) Zhu, Y.; Li, H.; Lin, K.; Wang, B.; Zhou, W. Synth. Commun. 2019, 49, 1721.

[55] Zhong, Y.-W.; Dong, Y.-Z.; Fang, K.; Izumi, K.; Xu, M.-H.; Lin, G.-Q. J. Am. Chem. Soc. 2005, 127, 11956.

[56] Wang, R.; Fang, K.; Sun, B.-F.; Xu, M.-H.; Lin, G.-Q. Synlett 2009, 2301.

[57] Si, C.-M.; Liu, Y.-W.; Mao, Z.-Y.; Han, P.; Du, Z.-T.; Wei, B.-G. Tetrahedron 2016, 72, 8091.

[58] (a) Liu, R. C.; Wei, J. H.; Wei, B. G.; Lin, G. Q. Tetrahedron: Asymmetry 2008, 19, 2731.

(b) Xarnod, C.; Huang, W.; Ren, R. G.; Liu, R. C.; Wei, B. G. Tetrahedron 2012, 68, 6688 .

(c) Zhou, W.; Nie, X.-D.; Zhang, Y.; Si, C.-M.; Zhou, Z.; Sun, X.; Wei, B.-G. Org. Biomol. Chem. 2017, 15, 6119.

[59] Kochi, T.; Ellman, J. A. J. Am. Chem. Soc. 2004, 126, 15652.

[60] Peltier, H. M.; Mcmahon, J. P.; Patterson; A, W.; Ellman, J. A. J. Am. Chem. Soc. 2006, 128, 16018 .

[61] Nicolaou, K. C.; Estrada, A. A.; Zak, M.; Lee, S. H.; Safina, B. S. Angew. Chem., Int. Ed. 2005, 44, 1378.

[62] Zhao, S.; Andrade, R. B. J. Am. Chem. Soc. 2013, 135, 13334

[63] Wang, X.; Xia, D.; Tan, L.; Chen, H.; Huang, H.; Song, H.; Qin, Y. Chem.-Eur. J. 2015, 21, 14602.

[64] Kokkonda, P.; Andrade, R. B. Org. Lett. 2019, 21, 9594

[65] Amat, M.; Alvarez, M.; Bonjoch, J.; Casamitjana, N.; Gràcia, J.; Lavilla, R.; Garcías, X.; Bosch, J. Tetrahedron Lett. 1990, 31, 3453.

[66] (a) Kazak, M.; Priede, M.; Shubin, K.; Bartrum, H. E., Poisson, J. F.; Suna, E. Org. Lett. 2017, 19, 5356.

(b) Jung, H. H.; Floreancig, P. E. J. Org. Chem. 2007, 72, 7359.

(Lu, Y.) 